\title{
Pertenencia y transmisión de nombres entre los Kanu’l en el Clásico Tardío
}

\section{Use and Transmission of Names among the Kanu'l during the Late Classic Period}

\author{
VeróNICA A. VÁZquEZ LóPEZ \\ Proyecto Arqueológico Yaxnohcah, University of Calgary / \\ Proyecto Arqueológico Regional Palenque, UNAM \\ FELIX KuPPRAT \\ Programa de Becas Posdoctorales, \\ Instituto de Investigaciones Antropológicas, UNAM
}

\begin{abstract}
Resumen: Los nombres personales son un elemento importante de los textos jeroglíficos mayas del período Clásico (250-900 d.C.) y su análisis aporta información sobre la configuración social y política de esta época. De interés primordial es el nombre colectivo conocido como "glifo emblema" que fungía como título real. En esta ocasión discutimos las implicaciones sociales del uso del apelativo k'uhul kanu'l ajaw, tratándose del glifo emblema más mencionado en el área maya durante el Clásico Tardío. En particular, determinamos los patrones de transmisión intergeneracional de este nombre y de otros segmentos nominales de la unidad social Kanu»l, para así problematizar los paradigmas de parentesco y los modelos de organización social que se han propuesto para el período en cuestión.

Palabras clave: Mayas, Clásico Tardío, dinastía Kanu'l, Calakmul, glifo emblema, unidades sociales.
\end{abstract}

AbSTRACT: Personal names are important elements of Maya hieroglyphic inscriptions of the Classic period (AD 250-900), and their analyses provide information about the social and political configuration of this time. The collective name known as "Emblem Glyph", which served as a regal title, is of particular interest here. In this occasion, we discuss the social implications of the use of the appellative k'uhul kanu'l ajaw, the most frequent Emblem Glyph in the Maya area, during the Late Classic period. We determine the pattern of intergenerational transmission of this and other names related to the Kanu'l social unit, in order to problematize the parentage paradigms and the models of social organization that have been proposed for this period.

Kerwords: Maya, Late Classic, Kanu’l dynasty, Calakmul, Emblem Glyph, social units.

RECEPCIÓn: 4 de agosto de 2016.

ACEPTACIÓN: 28 de noviembre de 2016.

DOI: 10.19130/iifl.ecm.2018.51.851 


\section{Introducción}

Al igual que la información calendárica, los nombres suelen formar una porción importante en los textos jeroglíficos del período Clásico (250-900 d.C.). ${ }^{1}$ En su mayoría, se trata de frases antroponímicas y están compuestos de nombres propios, epítetos y apelativos, incluyendo "títulos" y nombres descriptivos (Colas, 2004: 1-9). Ciertos segmentos de estas frases nominales son marcadores de identidades sociales, y los más claros son los llamados "glifos emblema" (GGEE), ${ }^{2}$ en los cuales nos enfocamos en el presente trabajo.

El glifo emblema (GE) fue identificado por Heinrich Berlin (1958), y debido a sus implicaciones sociopolíticas ha sido un objeto de estudio constante desde entonces (Berlin, 1959, 1960a, 1960b, 1977; Proskouriakoff, 1960, 1993; Barthel, 1968a, 1968b; Kelley, 1962, 1976; Marcus, 1973, 1976; Mathews y Justeson, 1984; Mathews, 1985, 1988, 1991; Houston, 1986; Stuart y Houston, 1994; Martin y Grube, 2000; Grube, 2005; Tokovinine, 2008; 2011; Helmke, 2012; Gronemeyer, 2012; entre otros). Berlin define el GE como un conjunto jeroglífico que incluye dos signos inalterables y un signo variable que es el "emblema" o "signo principal”. Posteriormente, los signos fijos fueron descifrados como K'UH (Ringle, 1988; Stuart y Houston, 1994: 5, 7), k'uh/ul], 'divino', y AJAW, ajaw, 'señor(a)' (Lounsbury, 1973; Mathews y Justeson, 1984: 203-205, 219). ${ }^{3}$ Por ende, la expresión que representa el GE suele traducirse como 'señor divino de [emblema]'; por ejemplo, Jasaw Chan K'awiil de Tikal, llevaba el epíteto k'uhul mutu'l ajaw, 'señor divino de Mutu'l'.

\footnotetext{
${ }^{1}$ Convenciones ortográficas: En este artículo se usan tres niveles de análisis de textos jeroglíficos. 1. La transliteración se marca con negritas. Fonogramas (o silabogramas) se escriben en minúsculas, logogramas en mayúsculas. Guiones medios conectan los grafemas de un solo bloque jeroglífico. Un signo de interrogación aislado o entre guiones marca un grafema con lectura desconocida, y si aparece al final de un grafema transliterado indica una lectura tentativa. Para referenciar signos de valor desconocido usamos, si no se indica otra cosa, los números del catálogo de J. Eric Thompson (1962). 2. La transcripción se marca con cursivas. Signos de interrogación indican transcripciones tentativas. Fonemas reconstruidos (subrepresentados) se escriben [entre corchetes]. Corchetes con puntos [...] indican pasajes que no se pudieron transcribir satisfactoriamente. 3. Traducciones se escriben entre 'comillas sencillas'. No se traducen nombres propios, por lo cual se representan como en la transcripción, pero marcados con mayúsculas iniciales. Expresiones que carecen de una traducción adecuada aparecen en cursivas.

Para la representación de palabras en maya clásico se usa el alfabeto y las normas establecidas por la Academia de Lenguas Mayas de Guatemala, con excepción del fonema /b’ para el cual se usa $b$, ya que en las lenguas mayas /b/ y /b'/ son alófonos. La ortografía de los sitios arqueológicos sigue las convenciones establecidas por los respectivos institutos nacionales que gestionan el patrimonio cultural (Instituto Nacional de Antropología e Historia en México, Instituto de Antropología e Historia en Guatemala, Institute of Archaeology en Belice e Instituto Hondureño de Antropología e Historia en Honduras); en caso de que no exista una ortografía institucionalmente establecida se usa la forma proporcionada por los proyectos arqueológicos correspondientes.

${ }^{2}$ En adelante GGEE para glifos emblema y GE para glifo emblema.

${ }^{3}$ En forma literal, aj-aw probablemente se puede traducir como 'el que habla con voz fuerte', 'el que grita' (Kaufman y Norman, 1984: 116, 139; Houston y Stuart, 1996: 295; Houston e Inomata, 2009: 131-132).
} 
Existen variantes que se han denominado "glifos emblema problemáticos" o “incompletos”. Estas aparecen sin el adjetivo k'uhul, 'divino', indicando un rango inferior (Houston, 1986; Grube, 2005), o bien sustituyen la expresión ajaw, 'señor', por otro término como maak, 'persona' —como en k'uhul k'antul'] maak, el GE de Caracol (Beetz y Satterthwaite, 1981: 115-116; Houston, 1986: 87; Martin y Grube, 2000: 87)—o winik, 'hombre' —en el GE k'uhul chatahn winik (ver Boot, 2005: 505-516; García Barrios y Velásquez, García 2010, 2016)—. No obstante, hay que estar conscientes de que el GE — por el elemento ajaw o su sustitutosiempre se refiere a una persona $-\mathrm{y}$ en algunos casos tal vez a varias- y nunca a un lugar o una entidad política en un sentido abstracto.

La forma completa del GE surgió a mediados del siglo v d.C., ${ }^{4}$ cuando a la forma del signo principal y la expresión ajaw se le agrega el adjetivo k'uhul, otorgando una carga de divinidad a la persona o las personas que lo ostentan. De acuerdo con varios autores (p. ej., Houston y Stuart, 1996: 295; Martin y Grube, 2000: 17), esto podría deberse al hecho de que las cortes estaban creciendo y con ello la competencia por el trono y la diversidad de los cargos sociopolíticos; así que se desarrolló una manera de identificar al personaje con mayor poder en la escala política agregando la característica de divino al gobernante mayor. No obstante, existen casos que hacen dudar del significado de este título, como por ejemplo el hecho de que en Motul de San José dos personajes hayan portado el título de 'señor divino' al mismo tiempo (Velásquez García, 2009: 131-132) o la ocurrencia de agrupaciones de distintos glifos emblema que no se relacionan con individuos específicos, como en los casos de la Estela A de Copán (Barthel, 1968a; Marcus, 1973: 913; 1976: 17-22; Schele y Miller, 1986: 161; Wagner, 2006: 157-159), del Altar 3 de Altar de los Reyes (Grube, 2008: 180-182) o de las vasijas que representan seres sobrenaturales como los wahy (Freidel, Schele y Parker, 1993: 190-192).

Mientras el significado complejo del título k'uhul ajaw y sus implicaciones siguen en discusión, existe otro debate en torno a los signos principales de los GGEE. Los signos principales frecuentemente representan topónimos (Stuart y Houston, 1994) que a menudo se interpretan como referentes a una ciudad en particular o a un territorio estatal (Marcus, 1973; 1976; Mathews, 1991). Algunos de ellos se han identificado como espacios concretos dentro de las ciudades (Tokovinine, 2008: 162-192), y otros son claramente de origen mítico (Helmke, 2012; Helmke y Kupprat, 2016). Independientemente de la calidad real o ima-

\footnotetext{
${ }^{4}$ Las primeras evidencias claras del epíteto k'uhul ajaw se encuentran en Tikal, en el Hombre de Tikal (406 d.C.) y en las Estelas 31 (445 d.C.), 9 (475 d.C.) y 17 (557 d.C.) (ver Colas, 2004: 238). En Calakmul, el primer GE completo se registra en 431 d.C. en la Estela 114 (Martin, 2005: 9-10). Otros GGEE de alrededor de 500 d.C. se encuentran en los monumentos de los cautivos de Dzibanché (Velásquez García, 2004: 92). Recientemente, dos ejemplos tempranos del GE de Cabeza de Murciélago fueron registrados en Naachtún (Cases y Lacadena, 2014), pero en el caso de la Estela 23, erigida en 361 d.C., la presencia del adjetivo k'uhul es insegura, mientras que la Estela 24 porta el GE completo, pero la fecha de elaboración del monumento es desconocida.
} 
ginaria de este lugar, el signo principal llegó a referir a un grupo de personas que reclamaban su procedencia de dicho sitio, adquiriendo una función como referente nominal.

En casos particulares, diferentes unidades políticas usaron el mismo GE, como Tikal y Dos Pilas (Houston, 1993: 97-102), o Palenque, Tortuguero y Comalcalco (Hoppan, 1996: 156-157; Martin y Grube, 2000: 165; Gronemeyer, 2004, I: $120-$ 124; Arellano Hernández, 2006: 143-146). En otros casos, se ha observado que algunos gobernantes llevaban dos GGEE, como sucede en varios sitios del área del Usumacinta o en Cancuén. Estos ejemplos reafirman que los signos principales funcionaron - dentro del GE- como nombres de unidades sociales. Las propuestas vigentes asocian el signo principal con linajes, casas reales o dinastías, pero aún hace falta una definición más detallada de tales conceptos. En este artículo queremos contribuir a dicha discusión a través de un estudio de caso en el cual analizamos los patrones de transmisión del apelativo k'uhul kanu'l ajaw, que al parecer fue utilizado en Dzibanché (probablemente durante todo el período Clásico) y en Calakmul durante el Clásico Tardío (Martin, 2005; Martin y Grube, 2008: 103-106; Velásquez García, 2008a, 2008b; Helmke y Awe, 2016a: 10-11), así como de otros segmentos nominales asociados a él.

El GE k'uhul kanu'l ajaw, 'señor divino de Kanu'l', fue el más mencionado durante el Clásico y fue portado por algunos de los gobernantes más poderosos de esta época. No obstante, hasta la fecha no se ha aclarado de manera contundente cuál fue la relación concreta entre los individuos que emplearon tal apelativo. Además, dicho GE también aparece en formas incompletas, sin el adjetivo k'uhul. De acuerdo con ejemplos provenientes de Dzibanché y El Resbalón (Nalda, 2004; Carrasco y Boucher, 1987; Esparza, 2012), el adjetivo k'uhul aparece en conjunto con la expresión kanu'l ajaw hacia mediados del siglo v y fue desde entonces utilizado por los gobernantes. No obstante, existen GGEE de Kanu'l del Clásico Tardío que carecen del adjetivo k'uhul. En algunos textos de La Corona, Naachtún, El Perú y Yaxchilán, k'uhul se encuentra sustituido por el clasificador femenino $i x$ - o ixik, refiriéndose a mujeres. En otros casos la omisión del adjetivo k'uhul se puede explicar por cuestiones discursivas, las cuales discutiremos más adelante.

Evidencias explícitas de lazos de parentesco entre los diferentes kanu'l ajaw y el mantenimiento de este título durante varias generaciones nos han llevado a considerar el uso del signo principal del glifo emblema como nombre de una unidad social. Antes de continuar con esta línea de argumentación, definiremos algunos conceptos relacionados con unidades sociales como linaje, casa y dinastía, entre otros, que consideramos pertinentes para nuestro estudio. 


\section{Conceptos relacionados con las unidades sociales}

El topónimo Kanu'l corresponde al nombre de una unidad social ${ }^{5}$ que frecuentemente ha sido considerada una dinastía, un término problemático porque es definitoriamente bastante borroso. A grandes rasgos, la dinastía se define como una secuencia de gobernantes de un país o región que heredan el poder; o como una sucesión de líderes poderosos de una región específica que pertenecen a la misma familia; o bien, como una familia en cuyos miembros se perpetúa el poder o la influencia política, económica, etc. De acuerdo con la última acepción, la dinastía puede incluir a todos los miembros de una familia, o por lo menos a los más influyentes. Así, el GE, y en particular el de Kanu’l, reflejaría su uso como nombre dinástico, en cuyos miembros se perpetúa el poder político, o bien, se transfiere. No obstante, estas definiciones se basan, a su vez, en el concepto de familia, el cual es, desde un punto de vista antropológico, altamente confuso. Aquí existe la opción de que la dinastía esté formada por los miembros de un linaje o por los integrantes de una casa real.

Por un lado, linaje se define como un grupo de personas unidas por lazos de sangre, basado principalmente en descendencia y que puede trazar su relación mediante vínculos genealógicos hasta un antepasado común por vía materna o paterna (Murdock, 1949: 42-47; Goodenough, 1970: 54-55; Gillespie, 2000: 468). Este modelo es el más usado para describir la organización social de los mayas del período Clásico (Haviland, 1970[1968], 1977, 1992; Hopkins, 1988; McAnany, 1995; Schele y Freidel, 1990; Sharer, 1993; entre otros).

Por otro lado, Claude Lévi-Strauss define a la casa como una "persona moral detentadora de una propiedad —material e inmaterial—, que se perpetúa por la transmisión de sus nombres, de su fortuna y de sus títulos en línea real o ficticia, tenida por legítima con la sola condición de que dicha continuidad pueda expresarse en el lenguaje del parentesco — real o ficticio- o de la alianza matrimonial o adopción-y, lo más a menudo, de los dos juntos" (Lévi-Strauss, 1986: 180). Aquí cabe aclarar que existen sistemas con características patrilineales marcadas que tienden a dar preferencia a las mujeres lineales sobre los varones colaterales cuando se trata del manejo de la herencia o de la sucesión, ${ }^{6}$

\footnotetext{
${ }^{5}$ Una unidad social se refiere a un individuo, un grupo, una comunidad o una organización que se considera un elemento discreto dentro de una sociedad o un grupo más grande, es decir, que funciona y actúa como una unidad dentro de una sociedad. Con lo anterior, se entiende que un individuo puede ser miembro de diferentes unidades sociales, de acuerdo a cómo se definan éstas, por ejemplo, una familia nuclear, un linaje, un grupo corporativo, etc. En este trabajo utilizamos el concepto de unidad social para referirnos a un grupo de individuos cuyos vínculos se trazan principalmente a través del parentesco consanguíneo, por afinidad y simbólico; y que comparten un sentido de pertenencia a un grupo, generando una unidad bien definida y que se distingue de otras, con las cuales puede establecer relaciones de alianza y/o competencia. Las unidades sociales de las que hablamos aquí son de estatus alto y con fuerte injerencia política. En particular, nos referimos a élites gobernantes.

${ }^{6}$ Herencia es la transmisión de bienes materiales e inmateriales y requiere de estrategias para asegurar su indivisibilidad, mientras la sucesión es un mecanismo mediante el cual se perpetúa una
} 
lo que ha sido denominado por algunos autores como linaje atenuado (Augustins, 1989; Robichaux, 2005). Al concepto de casa se asocia el de grupo corporativo, que ha recibido la atención de muchos antropólogos desde 1861, cuando Sir Henry Maine acuñó el término. Desde entonces ha sido objeto de redefiniciones continuas. A grandes rasgos podríamos decir que el grupo corporativo corresponde a un grupo de personas estable, selectivo y duradero que comparte colectivamente una propiedad, derechos, privilegios y/o responsabilidades; que tiene una identidad grupal bien definida y que tiene líderes (Maine, 1861; Honigmann, 1959: 360; para una discusión más amplia ver Hayden y Cannon, 1982).

Es importante señalar que las distintas unidades sociales comparten una necesidad inherente de permanencia y perpetuación en el tiempo y el espacio social, lo que se conoce como "modo de reproducción social" (Bourdieu, 1985; [1994] 1997; 2011; Augustins, 1989; ver Robichaux, 2005, para el caso mesoamericano), a través del desarrollo de "estrategias explicables y comprensibles en el contexto social global, donde los diferentes agentes o grupos de agentes luchan para reproducirse socialmente" (Bourdieu, 2011: 25). La lógica de los intercambios matrimoniales, las prácticas sucesorias y de herencia revelan diferentes modos de reproducción social de los grupos de parentesco (Robichaux, 1995; 2005; Bourdieu, 2011: 23).

El nombre y su transmisión también pueden llegar a tener un papel importante como marcador de pertenencia a una unidad social (Bourdieu, 1977; 2011; Lévi-Strauss, 1981; Klapisch-Zuber, 1987; 1990). El nombre es una frase nominal que hace referencia a un individuo o un grupo social (Colas, 2004). Los nombres que se transmiten pueden ser nombres propios individuales que son dados de padre a hijo, o de abuelo a nieto, etc. También hay nombres colectivos de familia, linaje, casa, entre otros, que afirman la solidaridad grupal marcando la pertenencia a una unidad social específica y que suelen ser indicadores de rango social y político (Klapisch-Zuber, 1987: 283-309).

Ante esta clasificación es necesario cuestionar cuál es el modelo más útil para caracterizar la identidad que codifican el GE y otros segmentos nominales en la sociedad maya del Clásico. Para acercarnos a esta cuestión, analizaremos algunos de los contextos en que aparece el GE de Kanu'l, con el fin de determinar su dinámica de transmisión.

\section{Sucesión y transmisión de nombres}

Para el análisis de los patrones de transmisión del GE, partimos de la premisa de que la utilización del GE por un individuo como parte de su nombre marca

posición de autoridad (Peniche Moreno, 2007: 309). La transmisión de poder y de títulos nobles entre diferentes grupos de parentesco es una sucesión que expresa el vínculo entre la organización social y la política (id.). 
su afiliación a una unidad social específica. El objetivo de este análisis es, por ende, determinar las características de tal unidad y los principios de afiliación. En diferentes regiones del área maya se ha observado que los k'uhul ajaw de un sitio suelen estar emparentados por ser o padre e hijo, o hermanos (Haviland, [1968] 1970; 1977; 1992; Hopkins, 1988; McAnany, 1995; Schele y Freidel, 1990; Sharer, 1993; entre otros). Esta observación forma la base de la propuesta frecuentemente implícita de que por lo general los gobernantes que comparten un mismo GE forman parte de un mismo patrilinaje y, por ende, de una dinastía. No obstante, existen ciertos datos que contradicen este patrón, por lo que consideramos que las relaciones sociales que determinan la transmisión del GE se deben comprobar de caso en caso. En esta ocasión nos enfocamos en la relación entre el GE Kanu’l en sus distintas variantes — con y sin el adjetivo k'uhul y otros modificadores - y la estructura de parentesco. Desafortunadamente, existen muy pocos indicadores textuales del Clásico que relaten de manera explícita las relaciones de parentesco que había entre los gobernantes que portaban dicho título. Por ello, empezaremos con la revisión de las menciones de los individuos femeninos relacionados con los Kanu’l, dado que tenemos datos más explícitos respecto a sus vínculos de parentesco.

\section{La transmisión del GE Kanu’l}

De las inscripciones provenientes del exterior de Calakmul se conocen varios nombres que incorporan el GE Kanu'l en su variante femenina, ixkanu'l ajaw, sin el adjetivo k'uhul (Figura 1). La evidencia más clara de que estas mujeres fueron hijas de los gobernantes de Kanu'l se encuentra en los textos del Panel 6 de La Corona ${ }^{7}$ (Figura 2). En los textos jeroglíficos grabados en este monumento se mencionan los nombres de tres ixkanu'l ajaw, que son explícitamente referidas como hijas ${ }^{8}$ de los gobernantes Tuun K'ab Hix, Ch'e'n y Ti' K'awiil, ${ }^{9}$ respectivamente, cada uno de los cuales portaba el GE completo k'uhul kanu'l ajaw.

Otros casos de mujeres que llevan el título ixkanu'l ajaw se han documentado en El Perú, Naachtún y Yaxchilán. En el caso de El Perú sólo se ha identificado a una mujer que lleva el GE en la forma ixkanu'l ajaw en su nombre. ${ }^{10}$ La Estela 34,

\footnotetext{
${ }^{7}$ Para los monumentos escultóricos de La Corona seguimos la denominación ajustada del Proyecto Arqueológico La Corona (Stuart et al., 2015a: 8-9). El Panel 6 también es conocido como Altar de Dallas, haciendo referencia a su ubicación actual en el Dallas Museum of Art.

${ }^{8}$ La relación hija-padre se expresa a través del signo T831. Simon Martin (2008a: 5-7) logró determinar el valor semántico de 'hija de (padre)' para este signo. Erik Boot (2009: 207) asignó la lectura fonémica de yatik, 'flor'. Albert Davletshin (comunicación personal, 2014) relacionó ambas identificaciones a través de la glosa atik, 'hijo/hija (de padre)', en chicomucelteco.

${ }^{9}$ Con base en las menciones de este nombre en otros contextos, Martin (1998: 110; 2008a: 4, nota de pie 5; Martin y Grube, 2000: 112) propone que ?-TI'-K'AWIIL es una variante del nombre de Yuhkno'm “Tok"” K'awiil, gobernante de Calakmul durante el primer tercio del siglo XIII.

${ }^{10}$ Los hallazgos recientes de las Estelas 43 (Navarro-Farr, Pérez y Menéndez, 2013: 7-46) y 44 (El Perú Regional Archaeological Project, 2013) han revelado el nombre de Ixikoom [...], y por sus
} 


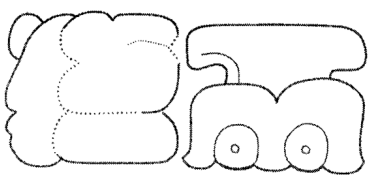

a
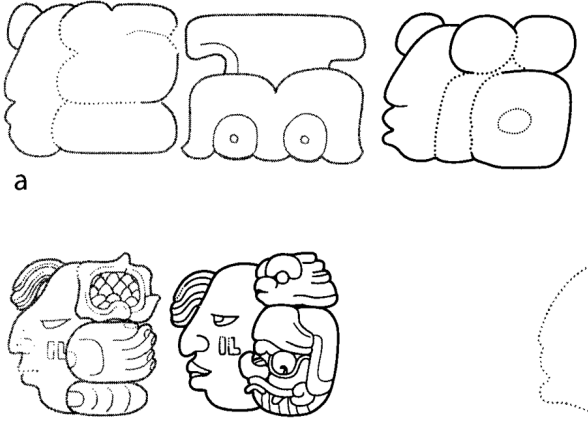

C

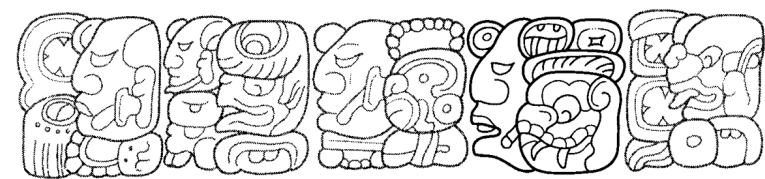

$\epsilon$
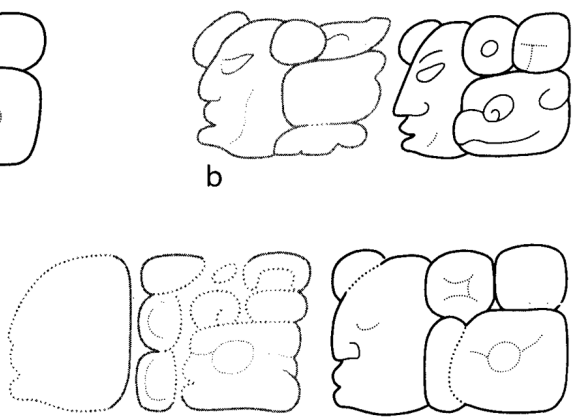

d
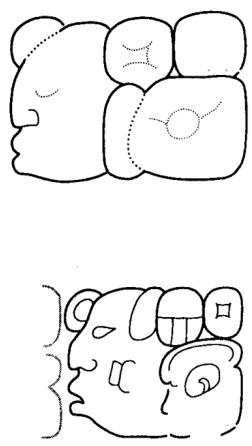

f

Figura 1. Frases antroponímicas de las ixkanu'l ajaw. a) Ix[...] Naah Ek' (La Corona, Panel 6); b) Ix[...|nal? (La Corona, Panel 6); c) Ixnaahb? K'abel (El Perú, Estela 34);

d) Ixti' Kan? (La Corona, Panel 6); Ixuh Chan Lem? con los títulos de la vasija invertida, ixajk'uhu'n y elk'in kalo'mte' (Yaxchilán, Estela 10); f) nombre propio desconocido (Naachtún, Estela 10). Dibujos de Felix Kupprat; a, b y d según dibujos de David Stuart (2013a), Simon Martin y Kim Leaman (Martin, 2008a: 3, tabla 1); c según dibujos de John Montgomery (2000: JM668, JM669); e según un dibujo de Linda Schele (Schele y Schele, 2000: no. 6212); f según el dibujo de Sylvanus Morley (1937, 5-1: Lám. 41e).

que se encuentra en el Museo de Arte de Cleveland, muestra a la señora Ix[...] K'abel?, vestida con el traje de red (Figura 3). En el texto que acompaña su imagen se relata que en esta representación Ix[...] K'abel? estuvo personificando a la Serpiente Acuática (Wanyerka, 1996: 87), y dos cartuchos grabados en su tocado contienen un texto jeroglífico que menciona su nombre con el apelativo ixkan[u'l] ajaw. En el rico ajuar funerario del Entierro 61 de El Perú, se encontró un recipiente de alabastro que lleva un texto corto que refiere a ix[... k'ab[el]? ixkan/u'l] ajaw como dueña del objeto (Navarro-Farr, Pérez y Menéndez, 2013: 77-82). Sin embargo, en ningún texto conocido hasta la fecha se aclara de manera explícita su relación con los gobernantes de Calakmul. El texto de la Estela 34 menciona

epítetos, sak wahyis y k'uhul chatahn winik, los investigadores del Proyecto Regional Arqueológico El Perú-Waka' han sospechado que se puede tratar de un segundo miembro femenino de los kanu'l. No obstante, el origen y la distribución social y geográfica de estos dos títulos siguen siendo temas de debate (Boot, 2005: 505-516; García y Velásquez, 2010, 2016; Grube et al., 2012: 21-23; Valencia Rivera et al., 2014; Vázquez López et al., 2016) y parecen ser mutuamente excluyentes; es decir, no se conoce a ningún kanu'l ajaw que haya portado el apelativo k'uhul chatahn winik o (k'uhul) sak wahyis. 


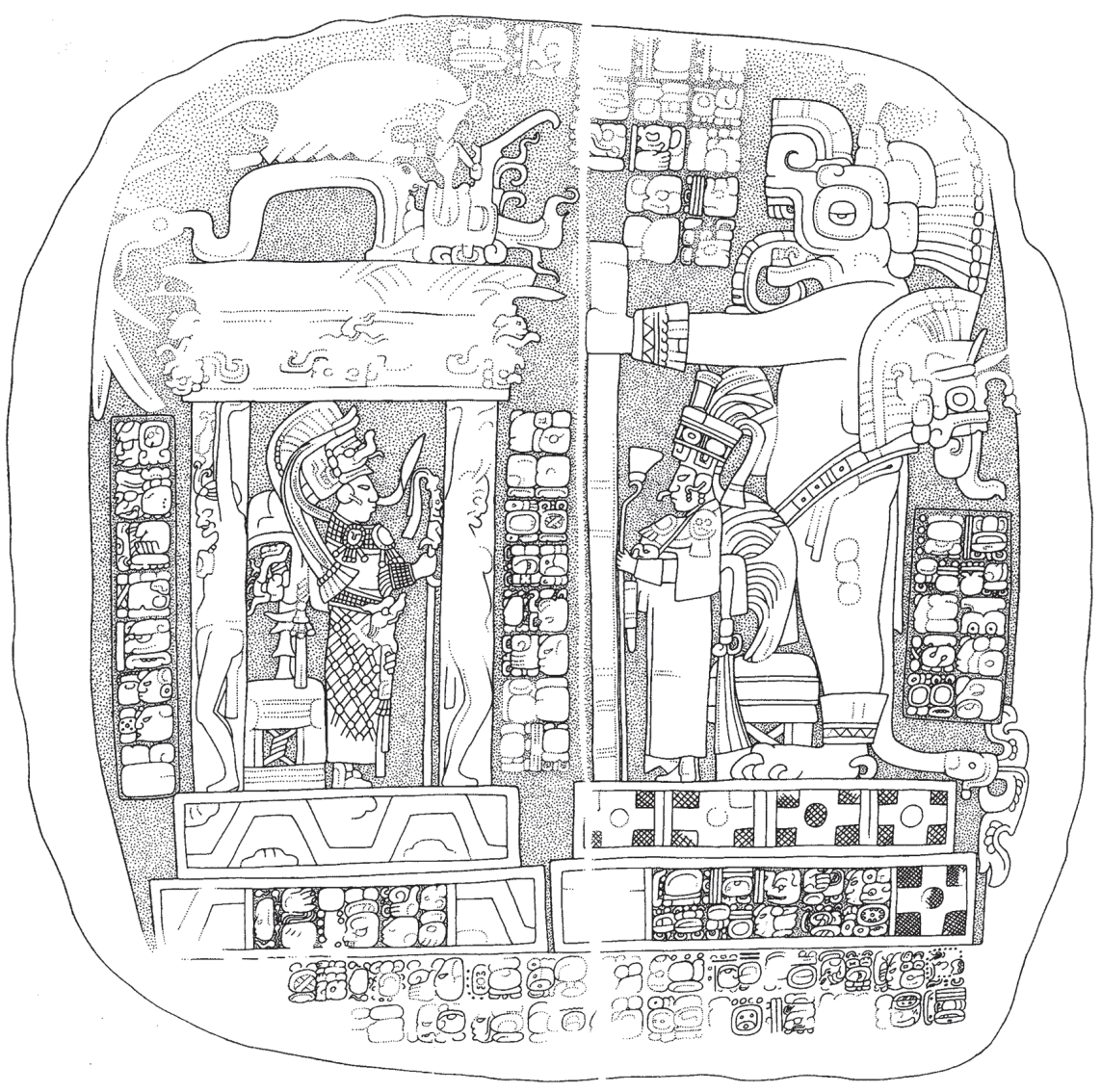

Figura 2. La Corona, Panel 6 (“Altar de Dallas”). Dibujo de David Stuart (2013a).

la entronización ${ }^{11}$ de Yuhkno'm Yihch'aak K'ahk', cuyo nombre incorpora el título k'uh[ul] kan[u'l] ajaw. En la parte del texto que se encuentra en el costado derecho del monumento se logra observar el nombre de Ch'e'n, el antecesor de Yihch'aak K'ahk', seguido por el nombre de una mujer que parece llevar el título k'uh[ul] [...]nal [waka' ajaw] (Martin, 2000: 116), el cual está estrechamente relacionado con individuos del Clásico Tardío de El Perú. ${ }^{12}$ A pesar de que la columna derecha

\footnotetext{
${ }^{11}$ Nótese que el predicado en B3 parece ser antipasivo (ch'am/aa/w 'tomó'), pero al mismo tiempo, parece incorporar el paciente ( $\left.k^{\prime} a w i i l\right)$. Predicados antipasivos pueden tomar el paciente como argumento único cuando se presenta un focalizador de agente (Kupprat, 2015: 185, nota de pie 113), el cual no se presenta en este caso. Además, el agente (Yihch'aak K'ahk') es explícito, así que el escriba probablemente quiso representar un predicado activo ( $\left.u l c c^{\prime} a m\left[a^{\prime}\right] w\right)$.

${ }^{12}$ Como nota Stanley Guenter (2007: 21-22), el título k'uh[ul] [...Jnal no necesariamente estuvo restringido a individuos de El Perú, ya que también aparece en textos de otros sitios de la región.
} 

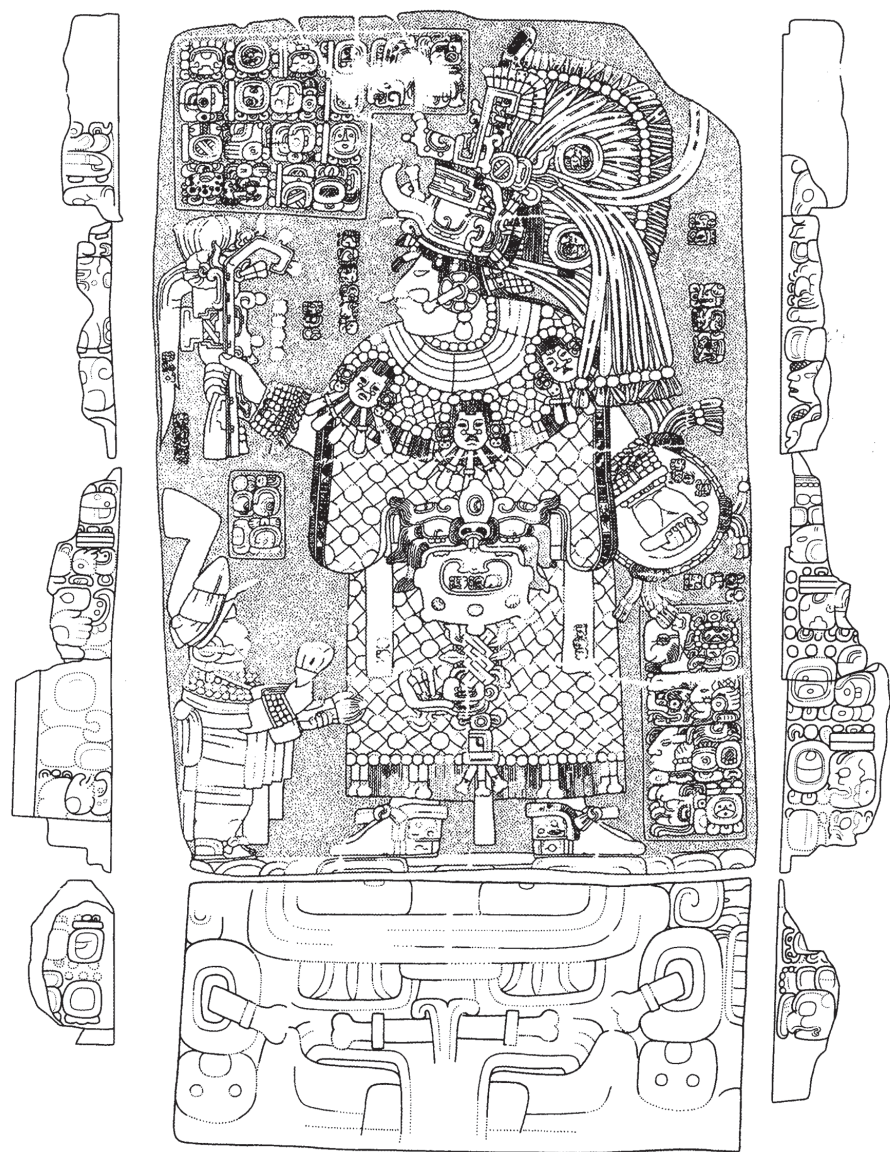

Figura 3. El Perú, Estela 34. Mosaico de dibujos de John Montgomery (2000: JM650 [basado en una fotografía de Ian Graham], JM651) y Felix Kupprat (laterales; basado en un dibujo de campo de Ian Graham y la reinterpretación de Kevin Brown en Wanyerka, 1996: 84, fig. 11).

del texto falta en esta sección, podemos plantear la hipótesis de que se trata de una expresión de parentesco, a través de la cual un individuo desconocido —probablemente la protagonista del monumento, Ix[...] K'abel? — se relaciona con Yuhkno'm Ch'e'n y con una mujer local. ${ }^{13}$ Yuhkno'm Ch'e'n además se menciona en el texto de la Estela 33 - la cual fue pareada con la Estela 34 de Ix $[\ldots]$ K'abel?-, como supervisor de la entronización del gobernante local K'ihnich

${ }^{13}$ La propuesta más probable es que se trate de los padres de Ix[...] K’abel? En estos casos, considerando también los ejemplos de La Corona y las relaciones de padres e hijas Kanu'l, el orden sintáctico tiene una estrecha relación con la importancia de los personajes involucrados en la frase, así el personaje de mayor rango se suele mencionar primero (Vázquez López, 2011, 2014). 
Bahlam, k'uh[ul] [.... nal wak[a'] ajaw, cuya imagen domina el frente de la estela. El patrón de las "estelas pareadas" se ha interpretado como indicador de relaciones de parentesco entre los individuos representados, que generalmente eran esposos (Proskouriakoff, 1961; Reese-Taylor et al., 2009; Stewart, 2009; García Barrios y Vázquez López, 2011, 2013, entre otros). ${ }^{14}$

El caso de Naachtún es el menos claro, ya que la única referencia conocida a una ixkanu'l ajaw aparece en la Estela 10 (Morley, 1937: láminas 41d-e, 151e). El nombre particular de esta mujer se perdió, pero la frase verbal k'al tuun, 'atadura de piedra', probablemente se refiere a ella. Sorprende la fecha en cuenta larga de 9.[16.]10.0.0 (761 d.C.) que se asocia con tal evento (Mathews y Parmington, 2005: 110), considerando que en este tiempo el prestigio de los Kanu'l había disminuido considerablemente y que, según Martin (Martin y Grube, 2000: 114115; 2008: 114-115; Martin, 2005), las referencias textuales contemporáneas de Calakmul mencionan a un individuo que se identificaba con el GE de la Cabeza de Murciélago en lugar del GE de Kanu'l. ${ }^{15}$ Por ende, las circunstancias de la presencia de la señora de Kanu'l en Naachtún permanecen oscuras, y esperamos que el registro de monumentos esculpidos en el sitio podrá proveer más datos en torno a dicha problemática. No obstante, es muy probable que las relaciones entre los Kanu’l y la élite gobernante de Naachtún fueran más antiguas. En la Estela 18 se representa a una mujer vistiendo el traje de red, el cual fue usado principalmente por mujeres relacionadas con la esfera Kanu'l (Mathews y Parmington, 2005: 108; Mathews et al., 2005: 671; Reese-Taylor et al., 2009: 56-57). En la estela no se ha identificado el apelativo ixkanu'l ajaw, pero aparece el topónimo uxte' tuun en la parte inferior de la escena, debajo de la cabeza de un cautivo, encima del cual está parado el personaje femenino. Coincidimos con Ana García Barrios y Verónica Vázquez López (2011: 77, con base en los comentarios de Alfonso Lacadena) en que esta expresión toponímica, que se refiere a Calakmul o un espacio específico dentro de la ciudad, podría indicar el lugar donde el cautivo fue humillado, ya que, ante la ausencia del prefijo de gentilicio $a j$, la lectura 'él de uxte' tuun' no se puede precisar. Por ende, es posible que se trate de otra señora Kanu'l que estableció una alianza matrimonial fuera de la ciudad de Calakmul.

Finalmente, encontramos un ejemplo más del apelativo ixkanu'l ajaw en el texto de la Estela 10 de Yaxchilán, como parte del nombre ixuh chan lem?, el cual corresponde a la madre de Yaxuun Bahlam IV. No obstante, desde un punto de vista histórico, es el caso más problemático de los señalados, por varias razones. Por un lado, todas las referencias a esta mujer son póstumas y aparecen tras un interregno poco entendido, después del cual se impuso Yaxuun Bahlam en el poder

${ }^{14}$ Es interesante que el par de las Estelas 33 y 34 fue complementado por otro monumento, la Estela 35 (Wanyerka, 1996: 81-82), la cual pudo haber tenido la imagen del hijo de Ix[...] K'abel?, ya que fue erigida casi 20 años después (Guenter, 2005: 372, 383).

${ }^{15}$ En el siglo vilı d.C., el GE de Cabeza de Murciélago no sólo (re)aparece en Calakmul (en las Estelas 62 y 59; Martin, 2005: 5-9), sino también en Oxpemul (Grube, 2005: 97-99) y, según Guenter (2005: 374-376), como parte del nombre de una mujer, en la Estela 32 de El Perú. 
gubernamental (Proskouriakoff, 1963: 163; Mathews, 1988: 176, 205-217; Martin y Grube, 2000: 127). Enseguida, el gobernante tuvo la necesidad de legitimar su posición en el discurso político enfatizando la descendencia prestigiosa de su madre. Por otro lado, de las nueve menciones de Ixuh Chan Lem? en Yaxchilán, ${ }^{16}$ sólo en la Estela 10 su nombre incluye el apelativo ixkanu'l ajaw. ${ }^{17}$ Esta observación coincide con la desaparición paulatina del GE de Kanu'l en el registro epigráfico general en la segunda mitad del siglo vill, por lo cual Yaxuun Bahlam recurrió a otros epítetos para elevar el estatus social de su madre. El nombre de ella muchas veces incluye el título sacerdotal ixajk'uhu'n, lo que implica una posición elevada en los ámbitos religioso y político (Zender, 2004: 164-195, 354-357). Además, en algunos textos (Estela 10 y Dinteles 32 y 53), Ixuh Chan Lem? lleva, al igual que Ix[...] K'abel? de El Perú, el título kalo'mte', el cual indica un rango político alto. De especial interés es la forma rara elk'in kalo'mte', 'kalo'mte' del oriente', que se aprecia en la frase nominal de Ixuh Chan Lem? en la Estela $10{ }^{18}$ Este título se opone directamente a ochk'in kalo'mte', 'kalo'mte' del occidente', ${ }^{19}$ llevado por su hijo Yaxuun Bahlam. Al vincularse con el oriente - y Calakmul se encuentra al este de Yaxchilán - Yaxuun Bahlam se posicionó, por lo menos de manera retórica, en el centro de una red de alianzas y relaciones de parentesco que cubrió diferentes subáreas del mundo maya, enfatizando su poder no sólo dentro, sino también fuera de Yaxchilán y en sus alrededores inmediatos. Durante su vida, Ixuh Chan Lem? no parece haber tenido el estatus de otras ixkanu'l ajaw, como Ix[...] K'abel de El Perú. Sin embargo, esta mujer llegó a jugar un papel de mucha importancia en el discurso representativo de su hijo, el cual apoyaba su poder en las alianzas con las élites de otros sitios, en este caso con los Kanu'l.

16 Dinteles 28 (C2-F1), 32 (H1-K3) y 53 (E3-G3); Estelas 10 (C2-E2), 11 (H1-G3; P2-P3), 34 (C4-D6) y 35 (C2-C4; D2-F2).

${ }^{17}$ En el texto del Dintel 53, el nombre se lee ixuh chan lem? ixajk'uhu'n [...] kal[o'm]te'. La expresión que precede a kallo'm/te' incluye el signo de la cabeza de serpiente con las fauces abiertas (Macri y Looper, 2003: 59, ACG/ACH), una cabeza humana (probablemente T1000 IX o T1008 XIB) y un signo K'IN (T544). Por la presencia del signo de serpiente, esta expresión se ha interpretado como título supremo con clasificador locativo ix?kan/u'l] kalo'mte', 'kalo'mte' (femenina) de Kanu'l' (ver p. ej. Tokovinine, 2008: 170). Este título fue registrado también en un texto recientemente hallado en La Corona (Stuart et al., 2015b). En su comentario, David Stuart propone la lectura tentativa elk'in? para el signo en cuestión.

${ }^{18}$ En la Estela 2 de Dos Caobas, el nombre de Ixuh Chan Lem? también contiene la expresión elk'in, en este caso seguida por yo[... In [...J ajaw en lugar de kalo'mte' (ver Tokovinine, 2007: 238).

${ }^{19}$ La expresión kalo'mte' se asocia con dos clasificadores. Uno es el clasificador de k'atunes que por lo general se compone de un numeral, la expresión winikhaab y kalo'mte'. El segundo se identifica desde las menciones más tempranas de este título e incorpora una dirección cardinal. Por lo general e independientemente de la procedencia geográfica, esta dirección cardinal es ochk'in, 'oeste', y existen pocas excepciones que incorporen otras direcciones. En el caso de la Estela 10 de Yaxchilán podemos asumir que la forma elk'in kalo'mte' es sumamente retórica (id.), aunque es interesante notar que, hasta donde podemos observar, los demás individuos de Calakmul no ocuparon la forma ochk'in kalo'mte'. En lugar del clasificador direccional parece que se prefería la variante localizada uxte' tuun kalo'mte', 'kalo'mte' de Uxte'tuun' (Calakmul, Estela 89, B5b-B6a; ¿Estela 9, C3-4?; Oxpemul, Estela 7, C3; Cancuén, Panel 1, D8-C9; ver Marcus, 1987: 80; Grube, 2005: 95-97). 
Con base en estos cuatro casos tenemos cierta dificultad en reconstruir los principios concretos de la transmisión del GE Kanu'l en su forma femenina. La evidencia triple del Panel 6 de La Corona indica una transmisión estrictamente patrilineal, en la cual la hija de un k'uhul kanu'l ajaw lleva el epíteto ixkanu'l ajaw, mientras su madre, cónyuge e hijos no obtienen este título. Desafortunadamente, en los demás casos no contamos con información definitiva respecto a los lazos de parentesco que existían entre las ixkanu'l ajaw y los k'uhul kanu'l ajaw. En el caso de $\mathrm{Ix}[\ldots]$ K'abel de El Perú es bastante plausible asumir que fue hija de Yuhkno'm Ch'e'n — sobre todo debido a las menciones de este gobernante y su sucesor Yihch'aak K'ahk' en las Estelas 33 y 34-, aunque hasta la fecha no existe evidencia directa para esta conexión. De ser correcta, esta propuesta sería otro ejemplo en que el título kanu'l ajaw fue transmitido de padre a hija, sin extenderse a los cónyuges o hijos de éstas, ya que K'ihnich Bahlam mantuvo el GE de El Perú. El caso de Naachtún queda inconcluso por falta de datos, pero en Yaxchilán vemos que Ixuh Chan Lem? tampoco transfirió su GE a su hijo, manteniendo el patrón de la transmisión patrilineal. Cabe mencionar que de las mujeres que fueron representadas en estelas de Calakmul, ninguna se ha podido relacionar con el GE de Kanu'l. Esto podría ser la culpa del mal estado en que se encuentran muchas de las inscripciones correspondientes, pero tomando en cuenta que probablemente se trataba de madres o cónyuges de los gobernantes locales, la ausencia del título ixkanu'l ajaw en estos monumentos coincide otra vez con un paradigma de transmisión estrictamente patrilineal.

Los principios de la trasmisión del glifo emblema entre los miembros masculinos de los Kanu'l son, sorprendentemente, menos claros, al igual que la información sobre las relaciones de parentesco entre ellos. Existe solo un ejemplo textual en que un k'uhul kanu'l ajaw se relaciona directamente con su hijo. Se trata de un texto inscrito en un espejo de pizarra (Figura 4) del Clásico Temprano, cuyo dueño tiene el nombre [...] Ch'e'n y lleva el título kan[u'l] ajaw, sin el adjetivo k'uhul 'divino'. Además, se especifica que es hijo de Yax Yopaat, cuyo nombre aparece con el GE completo. Esto reafirma que los padres transmitían el GE a sus hijos, pero en principio sin el elemento k'uhul. El texto retrospectivo del Elemento 5 de La Corona parece repetir este patrón: ${ }^{20}$ se narra el nacimiento de $y u[h] \mathrm{kno}\left[\mathrm{I}^{\mathrm{m}}\right]$ yihch'aak k'ahk' kan[u'll ajaw, lo que indica que por lo menos este gobernante llevaba el GE sin el adjetivo k'uhul desde su nacimiento. El adjetivo k'uhul parece haberse añadido al momento de tomar el poder (Colas, 2004: 241-242).

\footnotetext{
${ }^{20}$ Este elemento corresponde a un bloque de la una escalinata jeroglífica (“Conjunto B"), en la que se narran varios episodios de la vida de Yihch'aak K'ahk', desde su nacimiento en 649 d.C. (Mathews, 1979; Marcus y Folan, 1994: 23) hasta su muerte en 697 d.C. (Stuart y Baron, 2012: 195-196; Stuart et al., 2015c).
} 
Otro "príncipe" de los Kanu'l era el hermano menor (ihtz'iin winik) de Yihch'aak K'ahk' con el nombre Wahyis Utz'eh K'ab K'inich que aparece en dos textos de La Corona (Figura 5). Desafortunadamente, ni él ni su hermano llevan el apelativo kanu'l ajaw, así que este caso no ofrece más datos respecto a la transmisión del GE. Es posible que ellos fueran dos de los 'siete jóvenes, hijos del/de los señor(es) de Kanu'l' (huktikil ch'oktaak yunen kan/u'l] ajaw) que se mencionan en el Panel 1 de La Corona (J1-L1), pero la identidad de estos últimos aún es poco entendida.

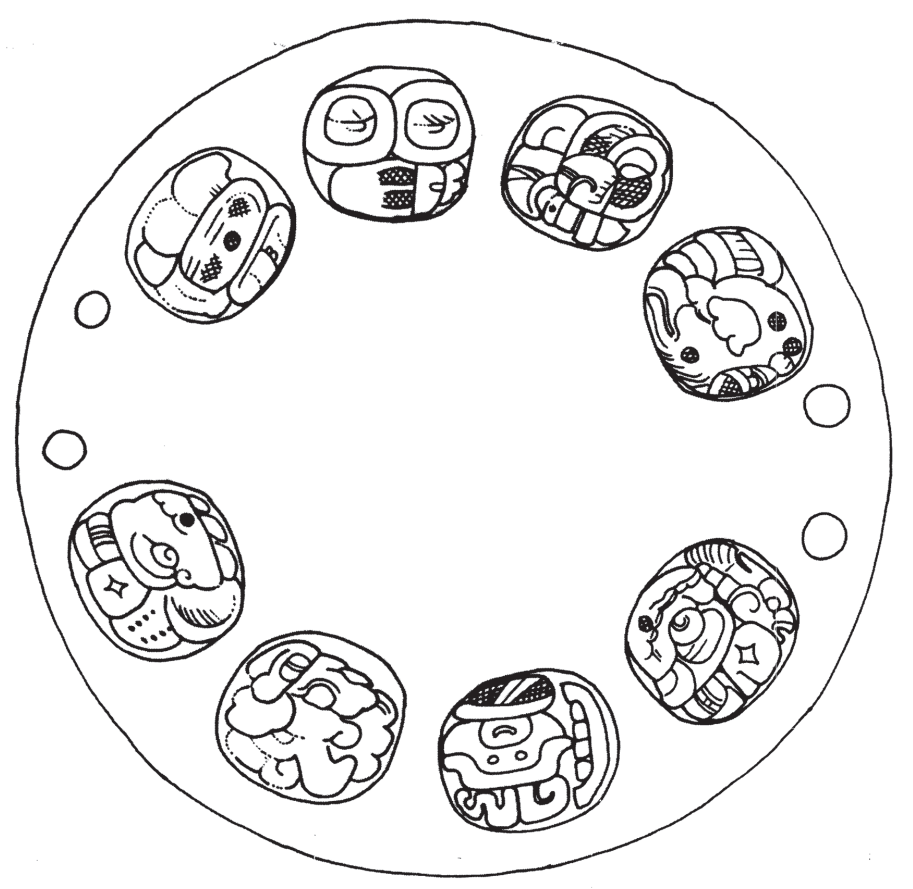

Figura 4. Inscripción en un espejo de pizarra de procedencia desconocida. Dibujo de Linda Schele (Schele y Schele, 2000: no. 6901).

También véase la fotografía publicada por Justin Kerr (2008: K4829).

Existen dos posibles indicadores adicionales para la relación de parentesco entre los k'uhul kanu'l ajaw, pero son aún más problemáticos que los referidos arriba. En la Estela 3 de Pol Box, por un lado, se menciona a varios individuos Kanu'l con el epíteto mam (literalmente 'abuelo'), pero en este contexto la expresión carece de marcas de posesión, así que la traducción 'ancestro' o 'viejo' como título honorífico o reverencial parece ser más adecuada (Esparza y Pérez, 2009: 9, nota de pie 6, 11; Lacadena, 2016). Por otro lado, algunas inscripciones del Clásico Tardío incluyen una cuenta dinástica que aparentemente empezaba con Ch'e'n II en la segunda mitad del siglo vI, pero este tipo de expresiones no 
necesariamente implican una relación parental entre los sucesores, y la aparente ruptura entre el reinado de Ch'e'n y su antecesor sigue siendo poco entendida (Martin, 2005: 7-8; para nuevas evidencias sobre la división dinástica ver Helmke y Awe, 2016b; Martin y Velásquez, 2016).

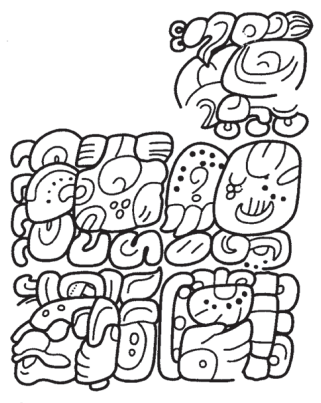

a

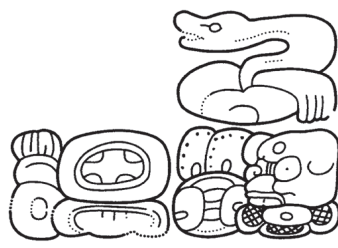

b

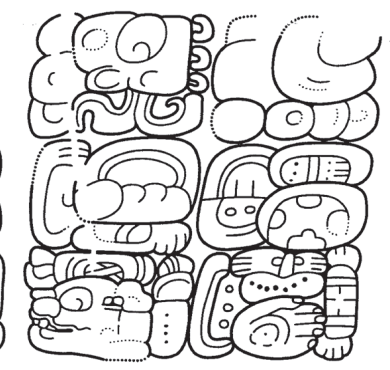

Figura 5. Frases paralelas que mencionan a Yuhkno'm Yihch'aak K'ahk' y el ihtz'in winik, Wahyis Utz'e[h] K'ab K'inich. a) Panel 1 de La Corona (P3-P5; dibujo de Felix Kupprat); b) Elemento 12 de La Corona (B2-D3; dibujo de Felix Kupprat según un dibujo de Peter Mathews [Stuart et al., 2015a: 2, fig. 1]).

Otros segmentos nominales de los Kanu'l

Además de los GGEE, se deben considerar otros segmentos nominales de los Kanu'l para precisar nuestras hipótesis respecto a las cuestiones de descendencia y afiliación social. La expresión yuhkno'm (literalmente 'sacudidor'; Esparza y Velásquez, 2013) encabeza los nombres personales de varios k'uhul kanu'l ajaw, por lo menos desde Yuhkno'm Ch'e'n I del siglo v d.C. Por ende, en el Clásico Tardío este nombre fue percibido como muy antiguo, como también indican sus menciones múltiples en las vasijas dinásticas (Martin, 1997: 857-861). Llama la atención que este nombre fue utilizado predominantemente por los Kanu'l, con sólo una excepción clara en el nombre de Yuhkno'm K'awiil de Río Azul, mencionado en la vasija K2914 (Kerr, 2008). No podemos descartar la posibilidad de que yuhkno'm marcara la afiliación a un patrilinaje (real y/o ficticio). Sin embargo, por la posición inicial de este segmento nominal y su asociación consistente con los gobernantes es probable que funcione como indicador de un estatus social superior, o incluso de realeza, parecido al epíteto k'ihnich empleado por otros grupos reales (Colas, 2004: 250-263), sin que necesariamente existan lazos de parentesco. No obstante, la clara predominancia del título entre los Kanu’l podría indicar una función doble.

Funcionalmente, semejante a la expresión yuhkno'm, existe otro segmento nominal que es característico de los Kanu’l. Una máscara funeraria de Calakmul — probablemente de Yihch'aak K'ahk' (Carrasco Vargas et al., 1999; Martin y Grube, 2000: 
109) — lleva un texto corto que empieza con la expresión ubaah, 'la imagen de', seguida por el nombre de Yuhkno'm Ch'e'n, el cual aquí incluye el teónimo asociado a la Serpiente Acuática yax chit juun witz' [naah kan] (Stuart, 2007). Martin (2008b) recientemente identificó a otro señor de los Kanu'l con un nombre parecido, [...] Naah Kan, en el Monumento 2 (Fragmentos 3 y 40) de Calakmul, el cual lleva el GE correspondiente, pero sin el clasificador $k^{\prime} u h u l .{ }^{21}$ Además, por lo menos una ixkanu'l ajaw, la madre de Yaxuun Bahlam IV de Yaxchilán, incorpora el teónimo facultativo juun [witz'] naah kan en su frase nominal en el Dintel 28. ¿Qué tipo de identidad expresa este teónimo en las frases nominales de los Kanu’l?

La Tabla 1 muestra la distribución de nombres que incluyen el nombre de la Serpiente Acuática Yax Chit Juun Witz' Naah Kan, o partes de él, en el Clásico (Colas, 2004: 263-264; Zamora Moya, s.f.). El primer ejemplo claro no proviene del Petén, sino de Copán. El nombre del decimosegundo gobernante de este sitio se escribe en varios monumentos como K'AK' u-TI' HUN-WITZ' K'AWIL y probablemente debe

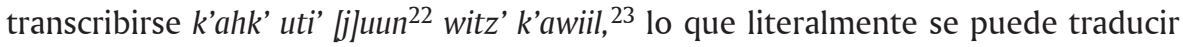
como 'fuego es la boca de Uno Agua Movida-K'awiil' o 'fuego es la boca del K'awiil Acuático'. No obstante, poco después empieza a aparecer el nombre de este ser como teónimo facultativo en los nombres de individuos mencionados en Calakmul. En ello, es interesante notar que no sólo los Kanu'l emplearon tal segmento nominal, sino por lo menos dos individuos más. El primero es la mujer representada en el costado posterior de la Estela 9 de Calakmul (Ruppert y Denison, 1943: lámina 48c; Marcus, 1987: 80), la cual probablemente fue la esposa del gobernante Yihch'aak K’ahk'. Su nombre propio incluye, además, el elemento 5-HUN-na (ho' $h u ' n)$, mismo que aparece en el nombre de una mujer en el Panel 6 de La Corona, por lo cual se ha propuesto que se trata de la misma persona (Vázquez López, 2015: 188-189). En el Panel 6, la señora Ho’ Hu'n está parada en un santuario de la serpiente acuática, lo que expresa su vínculo íntimo con esta deidad. Ni en el texto de Calakmul, ni en el de La Corona se logra distinguir un GE relacionado con dicho individuo, así que probablemente no era miembro de los Kanu’l. El segundo personaje con el nombre de la Serpiente Acuática que se menciona en Calakmul,

${ }^{21} \mathrm{El}$ GE de este individuo carece del clasificador k'uhul y es referido como yajaw, 'el señor de [alguien]', lo que posiblemente indica que se trata de un señor subordinado a un gobernante de mayor poder, sea de los Kanu'l o de otra unidad sociopolítica.

${ }^{22}$ Debido a la pérdida de la distinción entre / $\mathrm{h} / \mathrm{y} / \mathrm{j} /$ que se observa justamente durante el reinado de este gobernante en Copán (ver Carter, 2014: 46-47), HUN (el logograma para 'papel') aquí tiene la función de rebus para juun, 'uno'. El numeral juun no sólo sirve para indicar cantidades, sino también para marcar actores primordiales que fueron concebidos como prototipos de ciertos objetos o personas, como juun witz', 'Uno Agua Movida' (la serpiente acuática), juun ixim, 'Uno Maíz' (el dios del maíz) o juun ajaw, 'Uno Señor' (un héroe cultural) (Kupprat, en prep.).

${ }^{23}$ El teónimo K'awiil aquí probablemente refleja una propiedad serpentina. Esta ambigüedad entre kan chan y k'awiil se observa en diferentes nombres de gobernantes de Copán. Por ejemplo, el nombre Waxaklajun Ubaah K'awiil (Gobernante 13) es una variante "k'awiilizada" del teónimo Waxaklajun Ubaah Kan. De la misma manera, el nombre del Gobernante 12 (K'ahk' Uti' Juun Witz' K'awiil) se parece mucho al nombre de su antecesor (K'ahk' Uti' Chan Yopaat), debido a que una deidad serpentina, chan yopaat ('la serpiente-Yopaat'), está sustituida por otra, juun witz' k'awiil. 
sin formar parte de los Kanu'l, es el gobernante Yax Chit [...] Witz' Naah Kan, quien gobernó a mediados del siglo VIII (Martin y Grube, 2008: 112,115) y portaba el GE de Cabeza de Murciélago (Martin, 2005: 5).

Estos datos nos hacen pensar que el nombre de la serpiente acuática sirvió como un marcador de identidad de un grupo social en Calakmul, posiblemente de la corte real. Martin (comunicación personal con Baron, 2013: 387) identificó a la deidad Yax Chit Juun Witz' Naah Kan como dios patrono en la Estela 54 de Calakmul. Ello indicaría que el uso de este teónimo en los nombres de miembros de la corte tenía implicaciones religiosas, y posiblemente era situacional, relacionándose la personificación ritual de la Serpiente Acuática y un culto formal asociado a ella. En la Estela 34 de El Perú se narra de manera explícita que la personificación de la Serpiente Acuática por parte de Ix[...] K'abel?, una ixkanu'l ajaw, fue un acto importante durante la erección del monumento. ${ }^{24}$ El ejemplo de la Estela 9 de Calakmul refuerza la idea de que este culto pudo haber pertenecido a una unidad social que no sólo involucra a los miembros de un linaje (los Kanu'l), sino también a individuos afiliados a él mediante el uso de diversos mecanismos de cohesión social, como el matrimonio. Un modelo factible para entender esta unidad social extendida es la casa —en este caso la casa real, ${ }^{25}$ con sede en la Gran AcrópolisSi la hipótesis de una correspondencia entre la práctica ritual, la incorporación de teónimos facultativos en las frases nominales y la casa es correcta, debería haber existido un santuario de la Serpiente Acuática en algún sector de la Gran Acrópolis.

No es coincidencia que el teónimo Yax Chit Juun Witz' Naah Kan como segmento nominal fuese difundido en Yaxchilán y sus alrededores a partir de la segunda mitad del siglo vilI. El culto a esta deidad fue probablemente promovido por Yaxuun Bahlam IV de Pa' Chan, cuya madre, la ixkanu'l ajaw Ixuh Chan Lem?, porta este teónimo facultativo en el discurso retrospectivo del Dintel 28. A él también se debe que el nombre de la Serpiente Acuática fuera utilizado con más frecuencia por personajes relacionados con la casa real de Yaxchilán (Tabla 1) en las siguientes décadas, sobre todo por mujeres. ${ }^{26}$ Este patrón es muy parecido al del llamado "traje de red", que fue introducido y difundido por las señoras de Kanu'l a partir del siglo vir d.C., y que de hecho suele incorporar el tocado de la Serpiente Acuática (García y Vázquez, 2011).

\footnotetext{
${ }^{24}$ En la Estela 34 de El Perú la denominación de la Serpiente Acuática no forma parte de su nombre, ya que está precedido por la expresión u-ba-hi-li a-nu /u-baah-il-a’n/ '[ella] personifica' (F1-E2).

${ }^{25}$ Otros autores han preferido hablar de la "corte" en lugar de una casa real (Houston y McAnany, 2003: 37), para subrayar su rango e importancia con respecto a las casas no-reales en la sociedad maya clásica. Usamos el concepto de casa aquí por su relativa claridad definitoria y sus implicaciones teóricas. No es nuestra intención negar la posición sobresaliente de la casa real, ni la importancia del linaje como principio estructural en ella.

${ }^{26}$ Pierre Colas (2004: 191-195) demuestra que el teónimo Yax Chit Juun Witz' Naah Kan a veces sustituye al "título vasija" en las frases nominales de mujeres que aparecen mencionadas en los textos de Yaxchilán. Es posible que entonces este título también se relacione con el culto a la Serpiente Acuática, aunque también habría que considerar que se puede tratar de otro teónimo facultativo que remite a una deidad distinta.
} 


\begin{tabular}{|c|c|c|c|}
\hline Nombre & GE asociado & Monumento & $\begin{array}{l}\text { Temporalidad } \\
\text { (soporte) }\end{array}$ \\
\hline $\begin{array}{l}\text { K'ahk' Uti' Juun } \\
\text { Witz' K'awiil }\end{array}$ & $\begin{array}{l}\text { k'uhul T756d-pi } \\
\text { ajaw }\end{array}$ & $\begin{array}{l}\text { Copán, Altar K, Estelas 6, E, } \\
\text { e I (todos con el elemento } \\
\text { juun), entre otros }\end{array}$ & Desde 652 d.C. \\
\hline $\begin{array}{l}\text { Ixyax Chit Juun } \\
\text { Witz' Kan [...] } \\
\text { K'uh Ixik Ho' Hu'n }\end{array}$ & Desconocido & Calakmul, Estela 9 & 672 d.C. \\
\hline $\begin{array}{l}\text { Yax Chit Juun } \\
\text { Witz' Yuhkno'm } \\
\text { Ch'e'n }\end{array}$ & $\begin{array}{l}\text { [k'uhul kanu'l } \\
\text { ajaw] }\end{array}$ & $\begin{array}{l}\text { Calakmul, máscara funeraria } \\
\text { de la Tumba } 4 \text { (Estructura 2) }\end{array}$ & $\begin{array}{l}\text { Segunda mitad } \\
\text { siglo VII d.C. }\end{array}$ \\
\hline [...] Naah Kan & kanu'l ajaw & $\begin{array}{l}\text { Calakmul, Monumento } 2 \\
\text { (Fragmentos } 3 \text { y 40) }\end{array}$ & Clásico Tardío \\
\hline $\begin{array}{l}\text { Yax Chit }[\ldots] \text { Witz' } \\
\text { Naah Kan }\end{array}$ & $\begin{array}{l}\text { k'uhul } \\
\text { MURCIÉLAGO } \\
\text { ajaw }\end{array}$ & Calakmul, Estela 62 & 751 d.C. \\
\hline $\begin{array}{l}\text { Ixjuun Witz' Naah } \\
\text { Kan Ixuh Chan } \\
\text { Lem? Ixajk'uhu'n }\end{array}$ & [ixkanu'l ajaw] & Yaxchilán, Dintel 28 & 755 d.C. \\
\hline $\begin{array}{l}\text { Yax Chit Juun } \\
\text { Witz' Naah Kan Ux } \\
\text { Winikhaab Ajaw } \\
\text { Ajwinik Baak } \\
\text { Yaxuun Bahlam }\end{array}$ & $\begin{array}{l}\text { k'uhul Y2 ajaw } \\
\text { k'uhul pa' chan } \\
\text { ajaw }\end{array}$ & $\begin{array}{l}\text { Yaxchilán, Escalinata } \\
\text { Jeroglífica 2, Escalón } 7\end{array}$ & $\begin{array}{l}\text { Segunda mitad } \\
\text { siglo vIII d.C. }\end{array}$ \\
\hline $\begin{array}{l}\text { Ixjuun Witz' Naah } \\
\text { Kan Ixpaak Ti’? } \\
\text { Hu'n Winik Ixchak } \\
\text { Joloom }\end{array}$ & Desconocido & Yaxchilán, Dintel 1 & $\begin{array}{l}\text { Segunda mitad } \\
\text { siglo vill d.C. }\end{array}$ \\
\hline $\begin{array}{l}\text { Yax Pas[aj] Chan } \\
\text { Chab Ajaw Yax } \\
\text { [Chit] Juun Witz' } \\
\text { Naah Kan K'ahk' } \\
\text { Yip[yaj Chan] } \\
\text { K'awiil }\end{array}$ & $\begin{array}{l}\text { k'uhul T756d-pi } \\
\text { ajaw }\end{array}$ & $\begin{array}{l}\text { Copán, marco basal de la Es- } \\
\text { tela } \mathrm{N}\end{array}$ & ¿761? d.C. \\
\hline $\begin{array}{l}\text { Yax Juun Witz’? } \\
\text { [U]cha[']n Taj Mo' }\end{array}$ & $\begin{array}{l}\text { k'uhul pa' chan } \\
\text { ajaw }\end{array}$ & Laxtunich, Dintel 2 & 769 d.C. \\
\hline $\begin{array}{l}\text { Ixyax Chit Juun } \\
\text { Witz' Naah Kan }\end{array}$ & Ixpa' chan ajaw & Bonampak, Estela 2 & 789 d.C. \\
\hline $\begin{array}{l}\text { K'ahk' }[\ldots] \text { Chan } \\
\text { K'awiil [...] Yax } \\
\text { Chit Juun Witz' } \\
\text { Ukit Kan Lek }\end{array}$ & talol ajaw & Ek Balam, Bóveda 19 & 801-804 d.C. \\
\hline
\end{tabular}

Tabla 1. Nombres personales que incluyen referencias a la Serpiente Acuática. 


\section{Paradigmas de transmisión y variabilidad}

A pesar de que los datos presentados permiten, sin duda, cierto rango de interpretaciones, todo parece indicar que el GE de Kanu'l fue transmitido de manera patrilineal, de padres a hijos e hijas. La evidencia más clara proviene del Panel 6 de La Corona, donde la transmisión se refiere de manera explícita. Los demás casos comprueban que el GE no se transmitió de madres o esposas a sus hijos o esposos, respectivamente, ya que los hijos de las ixkanu'l ajaw llevan los GGEE de sus padres y nunca los de sus madres. Por ende, el uso del GE de Kanu'l fue exclusivo y no pudo ser pareado con otros, ${ }^{27}$ lo cual parece haber sido el paradigma más común entre los mayas del Clásico (Colas, 2004: 246-249). No obstante, en otras regiones del área maya, la combinación de GGEE fue una práctica frecuente, resultando en el uso de GGEE pareados en las frases nominales de los gobernantes. En varias ocasiones, las ocurrencias de glifos emblema pareados se han interpretado como resultados de la fusión de diferentes grupos de poder. Recientemente, se han publicado varios trabajos sobre estos casos (Biró, 2012; Gronemeyer, 2012; Helmke, 2012), así que aquí sólo discutimos algunos datos directamente relacionados con nuestra problemática.

En algunos casos, el uso de más de un GE por parte de los gobernantes sin duda servía para establecer lazos estrechos con héroes culturales y entidades sobrenaturales. En Palenque, por ejemplo, se nota que los gobernantes empezaron a nombrarse (y a ser nombrados retrospectivamente) k'uhul matwiil ajaw a partir del reinado de Kan Bahlam, y al parecer el título se relacionaba con ciertas actividades rituales y la dedicación de santuarios (Helmke, 2012: 97-99). Por ende, el GE de Matwiil no funcionaba como nombre de patrilinaje, sino más bien como título honorífico. No obstante, el otro GE principal de los gobernantes de Palenque, k'uhul baake'l ajaw, tampoco parece haberse transmitido estrictamente vía paterna antes del reinado de Janaab Pakal (Schele y Freidel, 1990: 221-223; Schele, 1992: 91-92; Stuart, 2005: 124, nota de pie 41; Martin y Grube, 2008: 161; Bernal, 2011: 32-33).

En Yaxchilán, los gobernantes se representaron con dos GGEE (Berlin, 1958: 115116; Mathews, 1988: 57-59). Ute Schüren (1992) sugirió que el GE secundario (Y2) fue introducido por una mujer, Ixpakal, a partir de su alianza matrimonial con Yaxuun Bahlam III. ${ }^{28} \mathrm{Si}$ esta hipótesis es correcta, contamos con un caso de trans-

\footnotetext{
27 Martin (2008b) recientemente mencionó la posibilidad de que se encuentre un GE de Kanu’l pareado con otro en el Afloramiento Rocoso Esculpido 2 en Calakmul. No obstante, la relación entre los textos e imágenes de esta escultura y los GGEE todavía es poco entendida y probablemente no contradice los patrones de transmisión del GE de Kanu'l.

${ }^{28}$ En el Escalón IV de la Escalinata Jeroglífica 3 de Yaxchilán (B5b y A7a; ver Graham 1982: 170) se observan ciertas diferencias entre la forma del GE de Ixpakal e Y2, como por ejemplo la falta del achurado y de la línea inferior en el elemento central, así como el marco ovalado ininterrumpido. Además, el signo principal lleva, en lugar del complemento -ji típico de Y2, un sufijo que probablemente tiene el valor -wi (más claro en el Dintel 27 de Yaxchilán, D2a; ver Graham y von Euw, 1977: 59). Esta observación hace dudar que el GE que lleva Ixpakal realmente es el mismo que portaron su hijo Kokaaj Bahlam y sus sucesores.
} 
misión vía materna. Sin embargo, tomando en cuenta que ambos GGEE hacen referencia a lugares mitológicos (Helmke, 2012), no podemos descartar la posibilidad de que la introducción del GE Y2 fuese una estrategia discursiva relacionada con la necesidad de Kokaaj Bahlam I de legitimar su posición política, similar al uso del GE de Matwiil en Palenque. Otro caso en que se ha propuesto la introducción de un GE por parte de una mujer es el del apelativo k'uhul baake'l ajaw en Tortuguero, pero las relaciones de parentesco de las personas involucradas no son suficientemente claras para confirmar este escenario (Gronemeyer, 2004: 146-147, 2012: 20-22; Gronemeyer y MacLeod, 2010: 53-54, nota de pie 56).

Otros ejemplos de GGEE pareados se encuentran en Bonampak y sus alrededores donde aparece el apelativo doble sak tz'i' ajaw k'uhul ak'e' ajaw, que está asociado con los sitios Sak Tz'i' y Bonampak (Anaya, Guenter y Zender, 2003: 187; Biró, 2005), así como la expresión xukalnaah ajaw k'uhul ak'e' ajaw, que combina el GE de Bonampak con el de Lacantún (Mathews, 1980; Beliaev y Safronov, 2004). Ejemplos adicionales incluyen los pares k'uhul yokib ajaw-k'ihna' ajaw, en Piedras Negras (Zender, 2002: 170-173; Biró, 2012: 49-50), y k’uhul ya[T626.544] ajawk'uhul [T174a.564] ajaw, en Cancuén ${ }^{29}$ (Fahsen y Demarest, 2001: 859, 862; Fahsen y Jackson, 2002: 792). Finalmente, podemos observar un par de glifos emblema pareados en el Monumento 171 de Toniná, en cuyo texto el gobernante K’ihnich Ihch'aak? Chapaht lleva no sólo el título de kalo'mte', sino también dos GGEE: el de popo'a' (Biró, 2012: 38-39) y un segundo que no ha sido descifrado. ${ }^{30}$

En ninguno de estos casos podemos decir con seguridad a qué evento se debe la unión de dos GGEE, pero generalmente se asume que este fenómeno se debe a la fusión de dos esferas políticas, sea por alianzas de beneficio mutuo, por la absorción política forzada o incluso por incidentes bélicos (Beliaev y Safronov, 2004; Biró, 2012: 56). No obstante, ya que es claro que los GGEE se refieren, estrictamente hablando, a individuos, también tenemos que explicar las implicaciones al nivel de las unidades sociales involucradas en estos procesos, así que no sólo hubo una fusión de las entidades políticas, sino también de los grupos sociales que las mantenían y sus emblemas.

\section{Discusión}

Con base en la evidencia presentada, la transmisión del GE en el caso de los Kanu'l parece seguir un paradigma patrilineal. De esta manera, tal GE debe en-

${ }^{29}$ Ya en la Estela 2 de Tres Islas aparecen estos dos GGEE que más tarde se asociarán con las dinastas de Cancuén y Machaquilá, respectivamente, pero no como GGEE pareados en una sola frase nominal, sino tal vez pertenecientes a diferentes individuos. Es probable que el texto y la iconografía de este monumento expresen una alianza matrimonial entre un k'uhul ya[T626.544] ajaw y una ix?[T174a.564] ajaw (ver Fahsen y Demarest, 2001: 859).

${ }^{30}$ Como mencionó David Stuart (en Martin y Grube, 2008: 187; Stuart, 2013b), este gobernante de Toniná está relacionado — a través de una expresión aún no entendida u-ma-?-li- con un personaje que probablemente es el gobernante [...] Ti' K'awiil de Kanu'l. 
tenderse como apelativo, que fue transmitido del padre a sus hijos (Figura 6); por ende, la dinastía de los Kanu'l es un patrilinaje. No obstante, el fenómeno de los GGEE pareados nos indica que este paradigma no se aplicaba siempre, ya que la ocupación simultánea de dos GGEE por un individuo indica la transmisión por dos linajes, lo que necesariamente involucra la transmisión de un GE por una mujer. Dichos casos se han documentado en muy pocas ocasiones y aparecen predominantemente en la región occidental del área maya. En consecuencia, parece que, bajo ciertas circunstancias, se rompió el paradigma de la transmisión patrilineal, probablemente con el fin de enfatizar las relaciones sociales de un individuo para fortalecer su prestigio social. Sin embargo, el hecho de que la pertenencia al linaje fuese marcada constantemente en los discursos oficiales, no significa que haya sido el único tipo de unidad social vigente. De hecho, la distribución del teónimo Yax Chit Juun Witz' Naah Kan en las frases nominales de las élites del Clásico indica que éste marcaba la pertenencia a una unidad más amplia que se puede interpretar como casa social, en este caso formada por un linaje dominante (los Kanu'l), así como a las mujeres de otras casas que se casaron y mudaron con los varones Kanu'l en un sistema patrilocal. Además, es posible que el linaje dominante cambiara en algún momento, sin que esto dañase la integridad de la casa, como lo sugiere el cambio del GE de Kanu'l a la Cabeza de Murciélago a mediados del siglo vIII d.C. El fenómeno de los GGEE pareados indica que, en situaciones excepcionales, el paradigma patrilineal de la transmisión del GE fue modificado cuando ello beneficiaba a la casa que, entonces, abarcaba a los miembros de dos linajes distintos, o bien, de un patri y un matrilinaje. ${ }^{31}$

De esta manera, hay que enfatizar que los modelos del linaje y la casa no se excluyen mutuamente. El concepto de casa simplemente enfatiza la cohesión social, los modos de reproducción social y la localidad, mientras el linaje subraya la descendencia y herencia paradigmática. Por ende, una casa social puede incluir linajes distintos, ya que ser miembro de una casa es posible por lazos de sangre, por afinidad o por parentesco simbólico. Así, la transmisión patrilineal del glifo emblema no se opone a la utilidad del modelo de la casa social para el Clásico maya, simplemente acentúa la descendencia de los individuos. La coexistencia de ambos tipos de unidades sociales aseguraba la eficiencia de la alianza matrimonial para establecer pactos entre las distintas casas. Al casarse, una esposa cambiaba de casa, pero no de linaje, así que la pertenencia a dos unidades sociales distintas (su linaje y su nueva casa) le permitía fungir como vínculo entre las dos, uniendo los intereses de ambas (Figura 7).

\footnotetext{
${ }^{31}$ Cabe aclarar que los datos en los que se apoya la reconstrucción de estos tres mecanismos - la marcación de pertenencia a una casa por prácticas rituales y nombres compartidos, el cambio del linaje dominante de una casa y la transmisión bilateral del GE- son, como sucede tantas veces en nuestro campo, muy fragmentados. Desafortunadamente, el corpus de imágenes y textos no permite corroborar estos mecanismos para toda el área maya y esperamos que futuros hallazgos ayuden a problematizar las hipótesis planteadas aquí.
} 


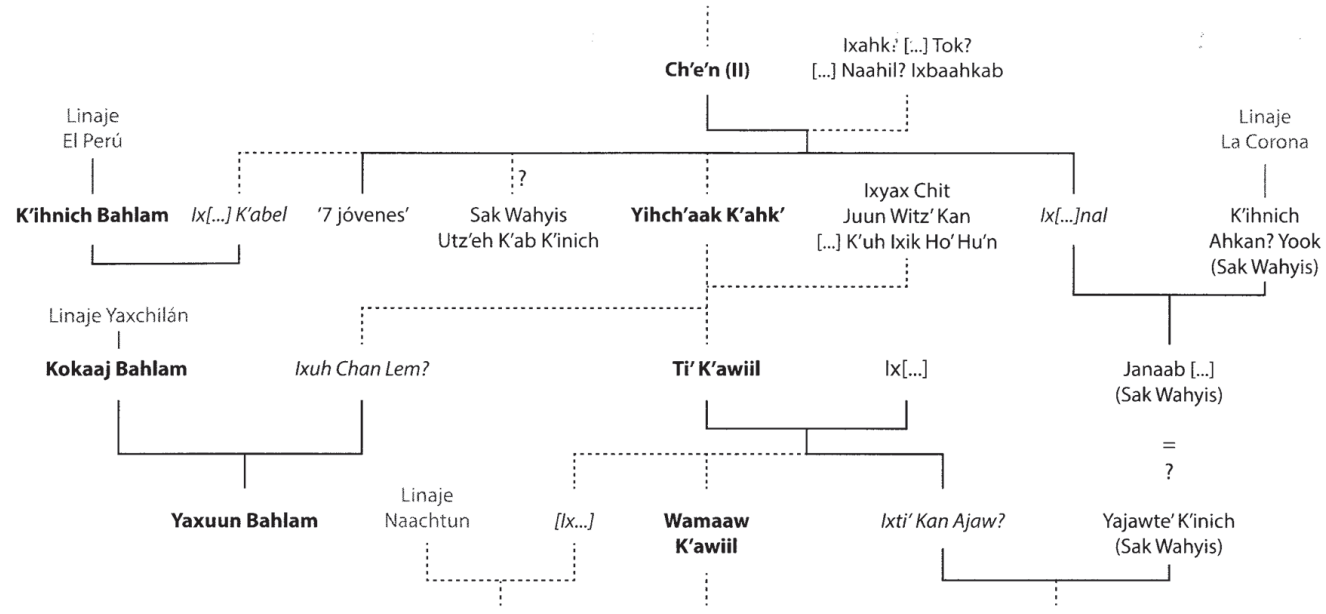

Figura 6. Relaciones de parentesco y alianzas matrimoniales entre los Kanu'l durante el Clásico Tardío. Los individuos que claramente portaron un glifo emblema completo se representan en negritas; las ixkanu'l ajaw son marcadas con cursivas. Las líneas discontinuas marcan relaciones hipotéticas. Para la genealogía de los linajes de La Corona véase el trabajo de Joanne Baron (2013: 330, fig. 7.3).

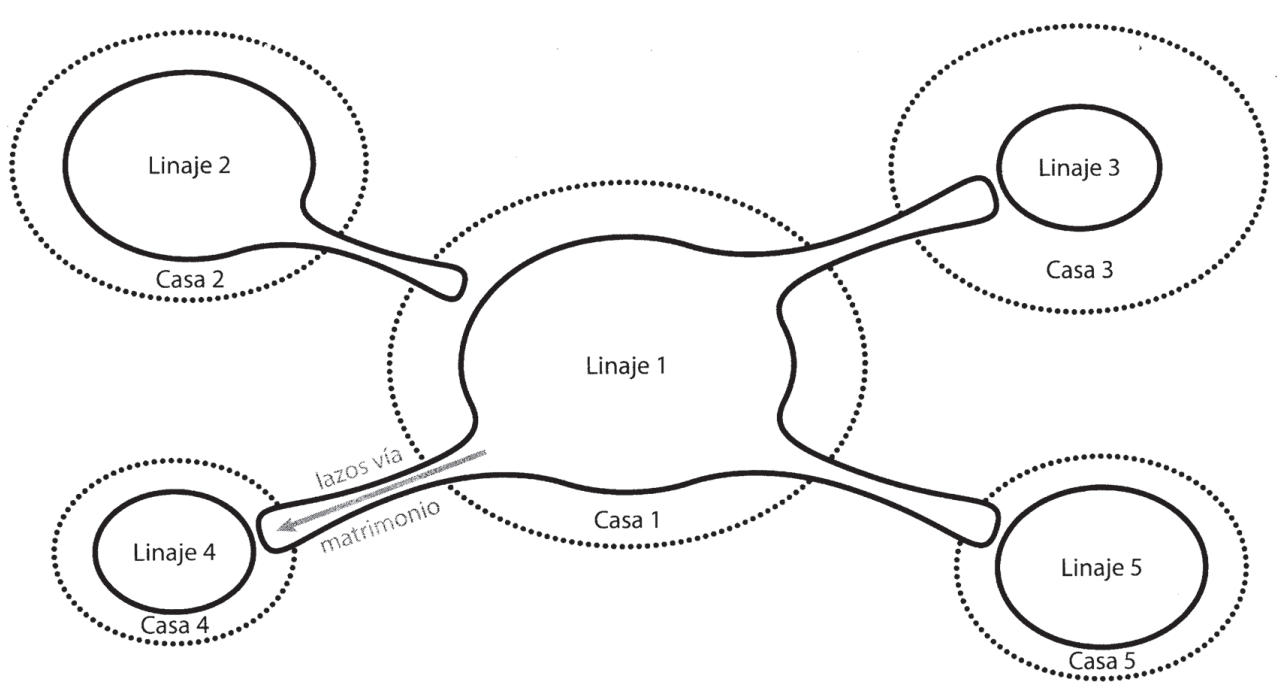

Figura 7. Modelo de la relación entre la casa social y el linaje. La casa abarca un linaje dominante, así como otros individuos afiliados. No obstante, ciertos miembros pueden cambiar de casa, estableciendo así vínculos duraderos entre dos linajes y las casas que dominan. 


\section{Conclusiones}

Es interesante observar que los datos disponibles apuntan a que los miembros Kanu'l que portaron la forma completa del GE o la incompleta kanu'l ajaw fueron personajes con un papel de suma importancia en la reproducción social y política del grupo. En el caso de las mujeres, fueron hijas de gobernantes que, a través de las alianzas matrimoniales con otras entidades, formaron amplios colectivos parentales con implicaciones políticas fuertes. Por su parte, los hombres que portaban el emblema coinciden con aquellos que fueron k'uhul ajaw; aunque los datos conocidos y el enfoque textual constante en los personajes reales aún no nos permiten determinar si se trata de un patrón constante o si más bien es coincidencia.

Por otro lado, cabe señalar que, aunque las estrategias de reproducción social de los Kanu'l tienden a pautas patrilineales en cuestiones de sucesión, las mujeres tuvieron un papel fundamental evidenciando un linaje atenuado, es decir, que las mujeres lineales tienen preferencia sobre los varones colaterales. Las alianzas entre las casas y las mujeres que las facilitaban eran causa de orgullo y fomentaban el prestigio de las unidades sociales involucradas. Sobre todo en el caso de las ixkanu'l ajaw, las mujeres que cambiaron de casa llegaban a ocupar un estatus más alto que sus esposos, como lo ilustra el caso de Ix[...] K’abel? de El Perú.

Las alianzas matrimoniales fungieron como estrategias para ampliar las redes sociales y, en los casos de las dinastías poderosas, también fomentaron la expansión y consolidación de sus espacios políticos. A nivel de grupos corporativos, estas alianzas generaban agrupamientos en pos de la salvaguarda de la propiedad material y simbólica con el fin de la perpetuación del grupo cuyo objetivo primordial destaca en la sociedad de casas (Peniche, 2007: 241). Finalmente, hay que señalar que el caso de la transmisión del título k'uhul kanu'l ajaw parece ser un caso típico para el Clásico maya, pero esto no significa que haya sido el modelo común en todas las áreas en todas las épocas. Consideramos que existían diferencias entre los significados del GE en distintos contextos sociales, y por eso es necesario analizar dicho título caso por caso.

\section{Agradecimientos}

Agradecemos al Consejo Nacional de Ciencia y Tecnología (CONACyT) por el apoyo económico a lo largo de nuestros estudios de doctorado, durante los cuales fue elaborado este texto. Gracias a David Stuart por el permiso de reproducir su dibujo del Panel 6 de la Corona, a Ricardo Gómez Palacios por habernos indicado el ejemplo de Laxtunich incluido en la tabla y a los dos revisores anónimos por sus valiosos comentarios y sugerencias. 


\section{Bibliografía}

Anaya Hernández, Armando, Stanley P. Guenter y Marc U. Zender

2003 "Sak Tz'i', a Classic Maya Center: A Locational Model Based on GIS and Epigraphy”, Latin American Antiquity, 14 (2): 179-191. DOI: https://doi. org/10.2307/3557594.

Arellano Hernández, Alfonso

2006 Tortuguero: una historia rescatada. México: Universidad Nacional Autónoma de México, Instituto de Investigaciones Filológicas, Centro de Estudios Mayas.

Augustins, Georges

1989 Comment se perpétuer? Devenir des lignées et destines des patrimoines dans les paysanneries européennes. Nanterre: Société d'ethnologie.

Baron, Joanne Parsley

2013 "Patrons of La Corona: Deities and Power in a Classic Maya Community", tesis de doctorado en Antropología. Filadelfia: University of Pennsylvania, Departamento de Antropología.

Barthel, Thomas S.

1968a "El complejo emblema”, Estudios de Cultura Maya, 7: 159-193. DOI: http:// dx.doi.org/10.19130/iifl.ecm.1968.7.700.

1968b "Historisches in den klassischen Mayainschriften", Zeitschrift für Ethnologie 93: 118-156.

Beetz, Carl.P. y Linton Satterthwaite

1981 The Monuments and Inscriptions of Caracol, Belize. Filadelfia: University Museum, University of Pennsylvania (University Museum Monograph, 45).

Beliaev, Dmitri y Alexander Safronov

2004 “Ак'е и Шукальнах: история и политическая география государств майя Верхней Усумасинты", Месоамерика, < http://www.mezoamerica.ru/indians/maya/ake.html > [Consultada el 16 de agosto del 2016].

Berlin, Heinrich

1958 "El glifo ‘emblema' de las inscripciones mayas”, Journal de la Société des Américanistes, 47: 111-119.

1959 "Los glifos nominales en el sarcófago de Palenque: Un ensayo", Humanidades, 10: $1-8$.

1960a "Más casos del glifo lunar en números de distancia", Antropología e Historia de Guatemala, 12 (2): 25-27.

1960b "Pomona: A New Maya Site (Preliminary Report)", Journal de la Société des Américanistes, Nouvelle Serie, 49: 119-121.

1977 Signos y significados en las inscripciones mayas. Guatemala: Instituto Nacional de Patrimonio Cultural. 
Bernal Romero, Guillermo

2011 "El señorío de Palenque durante la era de K’inich Janaahb' Pakal y K'inich Kan B'ahlam (615-702 d.C.)", tesis de doctorado en Estudios Mesoamericanos. México: Universidad Nacional Autónoma de México, Posgrado en Estudios Mesoamericanos.

Biró, Péter

2005 "Sak Tz'i' in the Classic Period Hieroglyphic Inscriptions", Mesoweb Publications, <http://www.mesoweb.com/articles/biro/SakTzi.pdf> [Consultada el 16 de agosto del 2016].

2012 "Politics in the Western Maya Region (II): Emblem Glyphs", Estudios de Cultura Maya, 39. DOI: http://dx.doi.org/10.19130/iifl.ecm.2012.39.58.

Boot, Erik

2005 Continuity and Change in Text and Image at Chichén Itzá, Yucatán, Mexico: A Study of the Inscriptions, Iconography, and Architecture at a Late Classic to Early Postclassic Maya Site. Leiden: CNWS Publications.

2009 "The Updated Preliminary Classic Maya-English, English-Classic Maya Vocabulary of Hieroglyphic Readings", Mesoweb Resources, <http://www. mesoweb.com/resources/vocabulary/Vocabulary-2009.01.pdf> [Consultada el 16 de agosto del 2016].

Bourdieu, Pierre

1977 Outline of a Theory of Practice. Cambridge: Cambridge University Press.

1985 "De la regla a las estrategias", entrevista con P. Lamaison. Terrains, 67. Mecanuscrito

1997 Razones prácticas. Sobre la teoría de la acción. Traducido por T. Kauf. Barcelona:

[1994] Editorial Anagrama.

2011 Las estrategias de la reproducción social, A. B. Gutiérrez (trad.). Buenos Aires: Siglo Veintinuno Editores.

Carrasco Vargas, Ramón y Sylviane Boucher Le Landais

1987 "Las escaleras jeroglíficas del Resbalón, Quintana Roo”, Primer Simposio Mundial sobre Epigrafía Maya 1986, pp. 1-21. Guatemala: Ministerio de Cultura y Deporte, Instituto de Antropología e Historia de Guatemala, National Geographic Society.

Carrasco Vargas, Ramón, Sylviane Boucher, Paula Álvarez González, Vera Tiesler Blos, Valeria García Vierna, Renata García Moreno y Javier Vázquez Negrete

1999 "A Dynastic Tomb from Campeche, Mexico: New Evidence on Jaguar Paw, a Ruler of Calakmul”, Latin American Antiquity, 10 (1): 47-58. DOI: https://doi. org/10.2307/972210.

Carter, Nicholas P.

2014 "Space, Time, and Texts: A Lanscape Approach to the Classic Maya Hieroglyphic Record", Archaeologies of Text: Archaeology, Technology, and Ethics, pp. 31-58, Matthew T. Rutz and Morag M. Kersel (eds.). Oxford, Filadelfia: Oxbow Books. 
Cases, Ignacio y Alfonso Lacadena

2014 “Operación III.5: Estudios Epigráficos, Temporada 2014”, Proyecto Petén-Norte Naachtun 2010-2014: Informe final de la Quinta Temporada de Campo 2014, pp. 371-384, Philippe Nondédéo, Julien Hiquet, Dominique Michelet, Julien Sion y Lilian Garrido (eds.), informe presentado al IDAEH. París: Laboratoire ArchAm UMR8096-CNRS, Université Paris 1 Panthéon-Sorbonne, CEMCA.

Colas, Pierre Robert

2004 Sinn und Bedeutung klassischer Maya-Personennamen: Typologische Analyse von Anthroponymphrasen in den Hieroglypheninschriften der klassischen Maya-Kultur als Beitrag zur allgemeinen Onomastik. Markt Schwaben: Anton Saurwein (Acta Mesoamericana, 15).

El Perú Regional Archaeological Project

2013 "Monument Find adds a New Chapter to Ancient Maya History", Newsroom, $<$ http://news.wustl.edu/news/Documents/Waka2013StelaWUSTLPressReleaseDraft-3(2).doc $>$ [Consultada el 20 de agosto del 2013].

Esparza Olguín, Octavio Q.

2012 "Las escaleras jeroglíficas de El Resbalón, Quintana Roo: Estudio de un conjunto de inscripciones mayas del Clásico temprano", tesis de maestría en Estudios Mesoamericanos. México: Universidad Nacional Autónoma de México, Posgrado en Estudios Mesoamericanos.

Esparza Olguín, Octavio Q. y Vania E. Pérez Gutierrez

2009 "Archaeological and Epigraphic Studies in Pol Box, Quintana Roo", The PARI Journal, 9 (3): 1-16.

Esparza Olguín, Octavio Q. y Erik Velásquez García

2013 "The YUK Logogram in Maya Hieroglyphic Writing”, The PARI Journal, 14 (1): $1-5$.

Fahsen, Federico y Arthur A. Demarest

2001 "El papel del Reino de Cancuen en la historia de las Tierras Bajas Mayas: Nuevos datos epigráficos", XIV. Simposio de Investigaciones Arqueológicas en Guatemala, 2000, pp. 858-874, Juan Pedo Laporte, Ana Claudia Suasnávar y Bárbara Arroyo (eds.). Guatemala: Museo Nacional de Arqueología y Etnología.

Fahsen, Federico y Sarah Elizabeth Jackson

2002 "Nuevos datos e interpretaciones sobre la dinastía de Cancuén en el periodo Clásico”, XV. Simposio de Investigaciones Arqueológicas en Guatemala, 2003, pp. 784-793, Juan Pedro Laporte, Héctor Escobedo y Bárbara Arroyo (eds.). Guatemala: Museo Nacional de Arqueología y Etnología.

Freidel, David A., Linda Schele y Joy Parker

1993 Maya Cosmos: Three Thousand Years on the Shaman's Path. Nueva York: W. Morrow. 
García Barrios, Ana y Verónica Amellali Vázquez López

2011 "The Weaving of Power: Women's Clothing and Protocol in the SeventhCentury Kingdom of Kaanu'l”, Latin American Indian Literatures Journal, 27 (1): 59-95.

2013 “Moda y protocolo femenino en el reino de Kanu'l (siglo vII d.C.)”, Maya Daily Lives, Proceedings of the 13th European Maya Conference (Paris, December 5-6, 2008), pp. 95-116, Philippe Nondédéo y Alain Breton (eds.). Markt Schwaben: Verlag Anton Saurwein (Acta Mesoamericana, 23).

García Barrios, Ana y Erik Velásquez García

2010 "Artistas, gobernantes y magos: el papel de los chatan winik en la sociedad maya", ponencia presentada en 15th European Maya Conference. Madrid: Sociedad Española de Estudios Mayas \& Museo de América.

2016 "Los hombres divinos de Chatahn: Historia y papel social de un 'linaje' maya del Clásico”, Arqueología Mexicana, 24 (139): 80-85.

Gillespie, Susan D.

2000 "Rethinking Ancient Maya Social Organization: Replacing 'Lineage' with 'House’”, American Antiquity, 102 (3): 467-484. DOI: 10.1525/aa.2000.102.3.467.

Goodenough, Ward H.

1970 Description and Comparison in Cultural Anthropology. Cambridge: Cambridge University Press.

Graham, Ian

1982

Corpus of Maya Hieroglyphic Inscriptions, Vol. 3, Part 1: Yaxchilán. Cambridge: Peabody Museum of Archaeology and Ethnology, Harvard University.

Graham, Ian y Eric von Euw

1977 Corpus of Maya Hieroglyphic Inscriptions, tomo 3-1. Cambridge, Peabody Museum of Archaeology and Ethnology, Harvard University.

Gronemeyer, Sven

2004 "Tortuguero, Tabasco, Mexiko: Geschichte einer klassischen Maya-Stadt, dargestellt an ihren Inschriften”, tesis de maestría en Antropología de América. Bonn: Universität Bonn, Philosophische Fakultät.

2012 "Statements of Identity: Emblem Glyphs in the Nexus of Political Relations", Contributions in New World Archaeology, 4: 13-40.

Gronemeyer, Sven y Barbara MacLeod

2010 "What Could Happen in 2012: A Re-analysis of the 13-Bak'tun Prophecy on Tortuguero Monument 6", Wayeb Notes, 34, <http:/www.wayeb.org/notes/ wayeb_notes0034.pdf> [Consultada el 16 de agosto del 2016].

Grube, Nikolai

2005 "Toponyms, Emblem Glyphs, and the Political Geography of Southern Campeche", Anthropological Notebooks, 11: 89-102.

2008 "Monumentos esculpidos: epigrafía e iconografía", Reconocimiento arqueológi- 
co en el sureste del estado de Campeche, México: 1996-2005, pp. 177-231, Ivan Šprajc (ed.). Oxford: Archaeopress (British Archaeological Reports International Series 1742).

Grube, Nikolai, Kai Delvendahl, Nicolaus Seefeld y Benjamino Volta

2012 "Under the Rule of the Snake Kings: Uxul in the 7th and 8th Century", Estudios de Cultura Maya, 40: 11-49. DOI: http://dx.doi.org/10.19130/iifl. ecm.2012.40.162.

Guenter, Stanley

2005 "Informe preliminar de la epigrafía de El Perú", Proyecto Arqueológico El PeruWaka': Informe No. 2, Temporada 2004, pp. 363-400, Héctor Escobedo y David Freidel (eds.). Guatemala: Instituto de Arqueología e Historia de Guatemala.

2007 "On the Emblem Glyph of El Peru", The PARI Journal, 8 (2): 20-23.

Haviland, William A.

1970 "Ancient Lowland Maya Social Organization", Archaeological Studies in Middle

[1968] America, pp. 93-117. Nueva Orleans: Tulane University, Middle American Research Institute (Publicación, 26).

1977 "Dynastic Genealogies from Tikal, Guatemala: Implications for Descent and Political Organization”, American Antiquity, 42 (1): 61-67. DOI: https://doi. org/10.2307/279461.

1992 "Status and Power in Classic Maya Society: The View from Tikal", American Anthropologist, 94 (4): 937-940. DOI: 10.1525/aa.1992.94.4.02a00140.

Hayden, Brian y Aubrey Cannon

1982 "The Corporate Group as an Archaeological Unit", Journal of Anthropological Archaeology, 1: 132-158. DOI: 10.1016/0278-4165(82)90018-6.

Helmke, Christophe

2012 "Mythological Emblem Glyphs of Ancient Maya Kings", Contributions in New World Archaeology, 3: 91-126.

Helmke, Christophe y Jaime J. Awe

2016a "Death Becomes Her: An Analysis of Panel 3, Xunantunich, Belize", The PARI Journal, 16 (4): 1-14.

2016b "Sharper than a Serpent's Tooth: A Tale of the Snake-Head Dynasty as Recounted on Xunantunich Panel 4", The PARI Journal, 17 (2): 1-22.

Helmke, Christophe y Felix Kupprat

2016 "Where Snakes Abound: Supernatural Places of Origin and Founding Myths in the Titles of Classic Maya Kings", Places of Power and Memory in Mesoamerica's Past and Present: How Sites, Toponyms and Landscapes Shape History and Remembrance, pp. 33-83, Daniel Graña-Behrens (ed.). Berlín: Ibero-Amerikanisches Institut, Gebr. Mann (Estudios Indiana, 9).

Honigmann, John

1959 The World of Man. Nueva York: Harpers and Brothers. 
Hopkins, Nicholas, A.

1988 "Classic Maya Kinship Systems: Epigraphic and Ethnographic Evidence for Patrilineality”, Estudios de Cultura Maya, 17: 87-121. DOI: http://dx.doi. org/10.19130/iifl.ecm.1988.17.596.

Hoppan, Jean-Michel

1996 "Nuevos datos sobre las inscripciones de Comalcalco", VIII Mesa Redonda de Palenque, 1993, pp. 153-158, Martha J. Macri y Jan McHargue (eds.). San Francisco: Pre-Columbian Art Research Institute.

Houston, Stephen D.

1986 Problematic Emblem Glyphs: Examples from Altar de Sacrificios, El Chorro, Río Azul, and Xultun. Washington, D.C.: Research Reports on Ancient Maya Writing. Center for Maya Research.

1993 Hieroglyphs and History at Dos Pilas: Dynastic Politics of the Classic Maya. Austin: University of Texas Press.

Houston, Stephen D. y Patricia A. McAnany

2003 "Bodies and Blood: Critiquing Social Construction in Maya Archaeology”, Journal of Anthropological Archaeology, 22: 26-41. DOI: 10.1016/S02784165(03)00006-0.

Houston, Stephen D. y Takeshi Inomata

2009 The Classic Maya. Nueva York, Cambridge: Cambridge University Press (Cambridge World Archaeology).

Houston, Stephen y David Stuart

1996 "Of Gods, Glyphs and Kings: Divinity and Rulership among the Classic Maya", Antiquity, 70: 289-312. DOI: https://doi.org/10.1017/S0003598X00083289.

Kaufman, Terrence S. y William M. Norman

1984 "Patterns of Substitution in Maya Hieroglyphic Writing", Phoneticism in Mayan Hieroglyphic Writing, pp. 77-166, John S. Justeson y Lyle Campbell (eds.). Albany: Insitute for Mesoamerican Studies, University of New York.

Kelley, David

1962 "Fonetismo en la escritura maya", Estudios de Cultura Maya, 2: 277-318. DOI: http://dx.doi.org/10.19130/iifl.ecm.1962.2.226.

1976 Deciphering the Maya Script. Austin: University of Texas Press.

Kerr, Justin

2008 "Maya Vase Database: An Archive of Rollout Photographs", Foundation for the Advancement of Mesoamerican Studies, < http://www.mayavase.com> [Consultada el 16 de agosto de 2015].

Klapisch-Zuber, Christiane

1987 Women, Family, and Ritual in Renaissance Italy. Chicago: The University of Chicago Press. 
1990 La maison et le nom. Stratégies et rituels dans l'Italie de la Renaissance. Paris: École des Hautes Études en Sciences Sociales.

Kupprat, Felix

2015 "La memoria cultural y la identidad maya en el periodo Clásico: una propuesta de método y su aplicación a los casos de Copán y Palenque en el siglo vII d.C.”, tesis de doctorado en Estudios Mesoamericanos. México, Universidad Nacional Autónoma de México, Posgrado en Estudios Mesoamericanos.

En prep. "Textual Reconstruction of Classic Maya Inscriptions: What Adaptions and Copies Tell Us about Scribes and the Practice of Writing", Maya Studies.

Lacadena García-Gallo, Alfonso

2016 "Evolución de las formas reverenciales mayas asociadas a los títulos políticos de rango y cargo desde el periodo Clásico hasta la época colonial", ponencia presentada en el $X$ Congreso Internacional de Mayistas. Izamal: Universidad Nacional Autónoma de México.

Lévi-Strauss, Claude

1981 La vía de las máscaras. México: Siglo XXI.

1986 Palabras dadas. Madrid: Espasa-Calpe.

Lounsbury, Floyd G.

1973 "On the Derivation and Reading of the 'Ben-Ich' Prefix", Mesoamerican Writing Systems: A Conference at Dumbarton Oaks, October 30th and 31st, 1971, pp. 99-143, Elizabeth P. Benson (ed.). Washington, D.C.: Dumbarton Oaks Research Library and Collections.

Macri, Martha J. y Matthew G. Looper

2003 The New Catalog of Maya Hieroglyphs, Volume 1: The Classic Period Inscriptions. Norman: University of Oklahoma Press.

Maine, Sir Henry

1861 An Ancient Law. Nueva York: E. P. Dutton.

Marcus, Joyce

1973 "Territorial Organization of the Lowland Classic Maya”, Science, 180 (4089): 911-916. DOI: 10.1126/science.180.4089.911.

1976 Emblem and State in the Classic Maya Lowlands: An Epigraphic Approach to Territorial Organization. Washington, D.C.: Dumbarton Oaks, Trustees for Harvard University.

1987 The Inscriptions of Calakmul: Royal Marriage at a Maya City in Campeche, Mexico. Ann Arbor: University of Michigan, Museum of Anthropology.

Marcus, Joyce y William Folan

1994 "Una estela más del siglo v y nueva información sobre Pata de Jaguar, gobernante de Calakmul, Campeche, en el siglo vil”, Gaceta Universitaria, IV (15-16): 21-26. 
Martin, Simon

1997 "The Painted King List: A Commentary On Codex-Style Dynastic Vases", The Maya Vase Book, tomo 5, pp. 847-867, Justin Kerr y Barbara Kerr (eds.). Nueva York: Kerr Associates.

1998 "Investigación epigráfica de campo: 1995-1998", Informe Temporada 19971998, pp. 72-122, mecanuscrito, Archivo del Proyecto Arqueológico Calakmul.

2000 "Nuevos datos epigráficos sobre la guerra maya del Clásico", La guerra entre los antiguos mayas: Memoria de la Primera Mesa Redonda de Palenque, pp. 106124, Silvia Trejo (ed.). México: Instituto Nacional de Antropología e Historia.

2005 "Of Snakes and Bats: Shifting Identities at Calakmul”, The PARI Journal, 6 (2): 5-15.

2008a "Wives and Daughters on the Dallas Altar", Mesoweb, <http://www.mesoweb. com/articles/martin/Wives\&Daughters.pdf $>$ [Consultada el 16 de agosto del 2016].

2008b "Reading Calakmul", ponencia presentada en la VI Mesa Redonda de Palenque: Arqueología, imagen y texto. Palenque: Instituto Nacional de Antropología e Historia.

Martin, Simon y Nikolai Grube

2000 Chronicle of the Maya Kings and Queens: Deciphering the Dynasties of the Ancient Maya. Londres: Thames \& Hudson.

2008 Chronicle of the Maya Kings and Queens: Deciphering the Dynasties of the Ancient Maya, edición revisada. Londres: Thames \& Hudson.

Martin, Simon y Erik Velásquez García

2016 "Polities and Places: Tracing the Toponyms of the Snake Dynasty", The PARI Journal, 17 (2): 23-33.

Mathews, Peter

1979 "Notes on the Inscriptions of "Site Q"”, mecanuscrito.

1980 "Notes on the Dynastic Sequence of Bonampak, Part 1", Third Palenque Round Table, 1978, Part 2, pp. 60-73, Merle Greene Robertson (ed.). Austin: University of Texas Press.

1985 "Early Classic Monuments and Inscriptions", A Consideration of the Early Classic Period in the Maya Lowlands, pp. 5-55, Gordon R. Willey y Peter Mathews (eds.). Albany: State University of New York.

1988 The Sculptures of Yaxchilán. New Haven: Yale University.

1991 "Classic Maya Emblem Glyphs”, Classic Maya Political History: Hieroglyphic and Archaeological Evidence, pp. 19-29, T. Patrick Culbert (ed.). School of American Research Advanced Seminar Series. Cambridge: Cambridge University Press.

Mathews, Peter y John Justeson

1984 "Patterns of Substitution in Maya Hieroglyphic Writing", Phoneticism in Mayan Hieroglyphic Writing, pp. 185-231, John Justeson y Lyle Campbell (eds.). Albany: Insitute for Mesoamerican Studies, University of New York. 
Mathews, Peter y Alexander Parmington

2005 "Investigaciones epigráficas (Operación 6)", Proyecto Arqueológico Naachtun: Informe No. 1, Febrero-Abril de 2004, pp. 104-113, Martin Rangel y Kathryn Reese-Taylor (eds.). Guatemala: Instituto de Antropología e Historia de Guatemala.

Mathews, Peter, Kathryn Reese-Taylor, Marcelo Zamora y Alexander Parmington

2005 "Los monumentos de Naachtun, Petén”, XVIII Simposio de Investigaciones Arqueológicas en Guatemala, 2004, pp. 669-672, Juan Pedro Laporte, Bárbara Arroyo y Héctor Mejía (eds.). Guatemala: Museo Nacional de Arqueología y Etnología.

McAnany, Patricia A.

1995 Living with the Ancestors: Kinship and Kingship in Ancient Maya Society. Austin: University of Texas Press.

Montgomery, John

2000 "The Montgomery Drawings Collection", Foundation for the Advancement of Mesoamerican Studies, Inc., <http://www.famsi.org/research/montgomery/index.html $>$ [Consultada el 16 de agosto del 2016].

Morley, Sylvanus Griswold

1937 The Inscriptions of Petén. Washington, D.C.: Carnegie Institution of Washington (Carnegie Institution of Washington Publication, no 437), 5 tomos.

Murdock, George P.

1949 Social Structure. Nueva York: MacMillan.

Nalda Hernández, Enrique

2004 "Dzibanché: El contexto de los cautivos", Los cautivos de Dzibanché, pp. 1356, Enrique Nalda Hernández (ed.). México: Instituto Nacional de Antropología e Historia.

Navarro-Farr, Olivia, Griselda Pérez Robles y Damaris Menéndez Bolaños

2013 "Operación 1: Excavaciones en la Estructura M13-1", Proyecto Regional Arqueológica El Perú-Waka’: Informe No. 10 Temporada 2012, pp. 3-91, Juan Carlos Pérez Calderón (ed.). Guatemala: Dirección General del Patrimonio Cultural y Natural.

Peniche Moreno, Paola

2007 Ámbitos del parentesco: la sociedad maya en tiempo de la Colonia. México: CIESAS-Porrúa.

Proskouriakoff, Tatiana

1960 "Historical Implications of a Pattern of Dates at Piedras Negras, Guatemala", American Antiquity, 25 (4): 454-475. DOI: https://doi.org/10.2307/276633. 
1961 "Portraits of Women in Maya Art", Essays in Pre-Columbian Art and Archaeology, pp. 81-99, Samuel K. Lothrop (ed.). Cambridge: Harvard University Press.

1963 "Historical Data in the Inscriptions of Yaxchilán (Part I) “, Estudios de Cultura Maya, 3: 149-167. DOI: http://dx.doi.org/10.19130/iifl.ecm.1963.3.685.

1993 Maya History. Austin: University of Texas Press.

Reese-Taylor, Kathryn, Peter Mathews, Julia Guernsey y Marlene Fritzler

2009 "Warrior Queens among the Classic Maya", Blood and Beauty: Organized Violence in the Art and Archaeology of Mesoamerica and Central America, pp. 39-72, Heather Orr y Rex Koontz (eds.). Los Ángeles: Cotsen Institute of Archaeology Press.

Ringle, William.

1988 Of Mice and Monkeys: The Value and Meaning of T1016, the God C Hieroglyph. Washington, D.C.: Research Reports on Ancient Maya Writing. Center for Maya Research.

Robichaux, David

1995 "Les modes de perpétuation de groupes de parenté: la résidence et l'héritage à Tlaxcala (Mexique), suivis d'un modèle pour la Mesoamérique", tesis de doctorado en Etnología. Nanterre: Universidad de Paris X.

2005 "Principios patrilineales de un sistema bilateral de parentesco: residencia, herencia y el sistema familiar mesoamericano", Familia y parentesco en México y Mesoamérica, pp. 167-272, David Robichaux (ed.). México: Universidad Iberoamericana (Unas Miradas Antropológicas, 2).

Ruppert, Karl y John H. Denison

1943 Archaeological Reconnaissance in Campeche, Quintana Roo, and Peten. Washington, D.C.: Carnegie Institution of Washington (Publication, 543).

Schele, Linda

1992 "A New Look at the Dynastic History of Palenque", Handbook of Middle American Indians, Supplement 5: Epigraphy, pp. 82-109, Victoria Bricker (ed.). Austin: University of Texas Press.

Schele, Linda y David A. Freidel

1990 A Forest of Kings: The Untold Story of the Ancient Maya. Nueva York: Morrow.

Schele, Linda y Mary Ellen Miller

1986 The Blood of Kings: Dynasty and Ritual in Maya Art. Nueva York, Fort Worth: G. Braziller, Kimbell Art Museum.

Schele, Linda, and David Schele

2000 "The Linda Schele Drawings Collection", Foundation for the Advancement of Mesoamerican Studies, Inc., <http://research.famsi.org/schele.html> [Consultada el 16 de agosto del 2016]. 
Schüren, Ute

1992 "The Yaxchilán Emblem Glyphs: Indicators of Political Change and Expansion of a Classic Maya Polity”, Mexicon, 14 (2): 30-39.

Sharer, Robert J.

1993 "The Social Organization of the Late Classic Maya: Problems of Definition and Approaches", Lowland Maya Civilization in the Eighth Century A.D., pp. 91-109, Jeremy Sabloff y John S. Henderson (eds.). Washington, D.C.: Dumbarton Oaks.

Stewart, Daniel Maroni

2009 "Parentage Statements and Paired Stelae: Signs of Dynastic Succesion for the Classic Maya”, tesis de maestría en Antropología. Provo: Brigham Young University, Departamento de Antropología.

Stuart, David

2005 The Inscriptions from Temple XIX at Palenque: A Commentary. San Francisco: Pre-Columbian Art Research Institute.

2007 "Reading the Water Serpent as WITZ", Maya Decipherment: Ideas on Ancient Maya Writing and Iconography, <http://decipherment.wordpress. com/2007/04/13/reading-the-water-serpent/> [Consultada el 16 de agosto del 2016].

2013a "New Drawing of a La Corona Panel", Maya Decipherment: Ideas on Ancient Maya Writing and Iconography, <https://decipherment.wordpress. com/2013/01/23/new-drawing-of-a-la-corona-panel/> [Consultada el 16 de agosto del 2016].

2013b “Tonina's Curious Ballgame”, Maya Decipherment: Ideas on Ancient Maya Writing and Iconography, <http://decipherment.wordpress.com/2013/06/11/ report-toninas-curious-ballgame/> [Consultada el 16 de agosto del 2016].

Stuart, David y Joanne Baron

2012 "Análisis preliminar de las inscripciones de la Escalinata Jeroglífica 2 de La Corona”, Proyecto Arqueológico La Corona - Informe Final: Temporada 2012, pp. 187-219, Tomás Barrientos Q., Marcello A. Canuto y Jocelyn Ponce (eds.). Nueva Orleáns: Tulane University, Middle American Research Institute.

Stuart, David, Marcello A. Canuto y Tomás Barrientos Quezada

2015a "The Nomenclature of La Corona Sculpture”, La Corona Notes, 1 (2), <www. mesoweb.com/LaCorona/LaCoronaNotes02.pdf > [Consultada el 16 de agosto del 2016].

Stuart, David, Marcello A. Canuto, Tomás Barrientos Quezada y Maxime Lamoureux StHilaire

2015b "Preliminary Notes on Two Recently Discovered Inscriptions from La Corona, Guatemala”, Maya Decipherment: Ideas on Ancient Maya Writing and Iconography, <https://decipherment.wordpress.com/2015/07/17/preliminary-noteson-two-recently-discovered-inscriptions-from-la-corona-guatemala/> [Consultada el 16 de agosto del 2016]. 
Stuart, David, Marcello A. Canuto, Tomás Barrientos Quezada, Jocelyn Ponce y Joanne Baron 2015c "Death of the Defeated: New Historical Data on Block 4 of La Corona Hieroglyphic Stairway 2", La Corona Notes 1 (3), <www.mesoweb.com/LaCorona/ LaCoronaNotes03.pdf> [Consultada el 16 de agosto del 2016].

Stuart, David y Stephen D. Houston

1994 Classic Maya Place Names. Washington, D.C.: Dumbarton Oaks Research Library and Collection (Studies in Pre-Columbian Art and Archaeology, 33).

Thompson, J. Eric S.

1962 A Catalog of Maya Hieroglyphs. Norman: University of Oklahoma Press.

Tokovinine, Alexandre

2007 "Classic Maya Place Name Database Project, Mesoamerica", Foundation for the Advancement of Mesoamerican Studies, <http://www.famsi.org/reports/06054/> [Consultada el 16 de agosto del 2016].

2008 "The Power of Place: Political Landscape and Identity in Classic Maya Inscriptions, Imagery, and Architecture”, tesis de doctorado en Antropología. Cambridge: Harvard University, Department of Anthropology.

2011 "People from a Place: Re-Interpreting Classic Maya Emblem Glyphs”, Ecology, Power, and Religion in Maya Landscapes, pp. 91-106, Christian Isendahl y Bodil Liljefors Persson (eds.). Markt Schwaben: Anton Saurwein [Acta Mesoamericana, 23].

Valencia Rivera, Rogelio, Albert Davletshin, Hugo García Capistrán, Felix Kupprat y Verónica A. Vázquez López

2014 "Leyendo una estela: el contexto arqueológico, el texto y la imagen de la Estela 43 de Calakmul”, ponencia presentada en las Jornadas Académicas Sistemas de Escritura Mesoamericanos: Estado de la cuestión y problemas actuales. México: Universidad Nacional Autónoma de México, Instituto de Investigaciones Estéticas.

Vázquez López, Verónica A.

2011 "El parentesco dentro de la estructura politica de los mayas del Clásico: Un acercamiento epigráfico y lexicográfico al caso del señorío de Kaan[V]l”, tesis de maestría en Estudios Mesoamericanos. México: Universidad Nacional Autónoma de México, Posgrado en Estudios Mesoamericanos.

2014 "Social Units in the Sociopolitical Structure of the Late Classic Maya: The Case of the Kanu'l Dynasty", Socio-political Strategies among the Maya from the Classic Period to the Present, pp. 127-245, Verónica A. Vázquez López, Rogelio Valencia Rivera y Eugenia Gutiérrez González (eds.). Oxford: Archaeopress (BAR International Series, 2619).

2015 "Dinastías, linajes y casas: las unidades sociales mayas en el ámbito político de los Kanu’l en el Clásico Tardío", tesis de doctorado en Estudios Mesoamericanos. México: Universidad Nacional Autónoma de México, Posgrado en Estudios Mesoamericanos. 
Vázquez López, Verónica A., Felix Kupprat, Carlos Morales Aguilar, Hugo García Capistrán y Rogelio Valencia Rivera

2016 "Los cambios de poder en el juego interdinástico: los gobernantes de Calakmul de los siglos V a VIII d.C.”, XXIX Simposio de Investigaciones Arqueológicas en Guatemala, 2015, tomo 2, pp. 1101-1114, Bárbara Arroyo, Luis Méndez Salinas y Gloria Ajú Álvarez (eds.). Guatemala: Asociación Tikal.

Velásquez García, Erik

2004 "Los escalones jeroglíficos de Dzibanché", Los cautivos de Dzibanché, pp. 78103, Enrique Nalda Hernández (ed.). México: Instituto Nacional de Antropología e Historia.

2008a "En busca de Testigo Cielo (ca. 561-572 d.C.): El punzón de hueso del Edificio de los Cormoranes de Dzibanché", ponencia presentada en la VI Mesa Redonda de Palenque. Palenque: Instituto Nacional de Antropología e Historia.

2008b "Los posibles alcances territoriales de la influencia política de Dzibanché durante el clásico temprano: nuevas alternativas para interpretar menciones históricas sobre la entidad política de Kan”, El territorio maya: Memoria de la Quinta Mesa Redonda de Palenque, pp. 323-352, Rodrigo Liendo Stuardo (ed.). México: Instituto Nacional de Antropología e Historia.

2009 "Los vasos de la entidad política de 'Ik': Una aproximación histórico-artística: Estudio sobre las entidades anímicas y el lenguaje gestual y corporal en el arte maya clásico", tesis de doctorado en Historia del Arte. México: Universidad Nacional Autónoma de México, Posgrado en Historia del Arte.

Wagner, Elisabeth

2006 "Ranked Spaces, Ranked Identities: Local Hierarchies, Community Boundaries and an Emic Notion of the Maya Cultural Sphere at Late Classic Copán”, Maya Ethnicity: The Construction of Ethnic Identity from Preclassic to Modern Times, pp. 143-164, Frauke Sachse (ed.). Markt Schwaben: Anton Saurwein (Acta Mesoamericana, 19).

Wanyerka, Phil

1996 "A Fresh Look at a Maya Masterpiece", Cleveland Studies in the History of Art, 1: 72-97.

Zamora Moya, María Auxiliadora

s.f. La Serpiente de Agua en el periodo Clásico maya”, manuscrito, Universidad Complutense.

Zender, Marc

2002 "The Toponyms of El Cayo, Piedras Negras, and La Mar", Heart of Creation: The Mesoamerican World and the Legacy of Linda Schele, pp. 166-184, Andrea J. Stone (ed.). Tuscaloosa: University of Alabama Press.

2004 "A Study of Classic Maya Priesthood", tesis de doctorado en Arqueología. Calgary: University of Calgary, Department of Archaeology. 